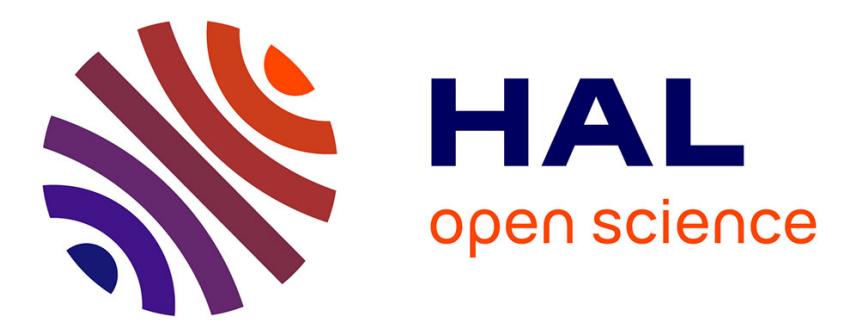

\title{
Modified parameter-setting-free harmony search (PSFHS) algorithm for optimizing the design of reinforced concrete beams
}

Mahmoud Shaqfa, Zoltán Orbán

\section{- To cite this version:}

Mahmoud Shaqfa, Zoltán Orbán. Modified parameter-setting-free harmony search (PSFHS) algorithm for optimizing the design of reinforced concrete beams. Structural and Multidisciplinary Optimization, In press, 10.1007/s00158-019-02252-4 . hal-02133774

\section{HAL Id: hal-02133774 \\ https://hal.science/hal-02133774}

Submitted on 19 May 2019

HAL is a multi-disciplinary open access archive for the deposit and dissemination of scientific research documents, whether they are published or not. The documents may come from teaching and research institutions in France or abroad, or from public or private research centers.
L'archive ouverte pluridisciplinaire HAL, est destinée au dépôt et à la diffusion de documents scientifiques de niveau recherche, publiés ou non, émanant des établissements d'enseignement et de recherche français ou étrangers, des laboratoires publics ou privés. 


\title{
Modified parameter-setting-free harmony search (PSFHS) algorithm for optimizing the design of reinforced concrete beams
}

\author{
MAHMOUD SHAQFA ${ }^{1}$ (iD \\ Earthquake Engineering and Structural Dynamics Laboratory (EESD), \\ School of Architecture, Civil and Environmental Engineering (ENAC), \\ École polytechnique fédérale de Lausanne (EPFL), \\ CH-1015 Lausanne, Switzerland. \\ Tel.: +41216933297 \\ mahmoud.shaqfa@epfl.ch

\section{ZOLTÁN ORBÁN} \\ Department of Structural Engineering, \\ Faculty of Engineering and Information Technology, \\ University of Pécs, \\ Boszorkány u. 2, H-7624 Pécs, Hungary. \\ orbanz@mik.pte.hu \\ Publisher link: DOI: $10.1007 / \mathrm{s} 00158-019-02252-4$ \\ Journal: Structural and Multidisciplinary Optimization
}

\begin{abstract}
The design of RC members with nontraditional methods is demanding due to the large number of unknown variables inherent in the design process. The complexity of the $\mathrm{RC}$ beams design optimization problem has led to many oversimplified models, so as current metaheuristic search algorithms can deal with it efficiently. In this paper, the optimization design model of $\mathrm{RC}$ beams has been introduced by new design variables, while augmented some; accordingly enhanced the solving algorithm. A new enhanced parameter-setting-free harmony search algorithm has been proposed to solve the model. Furthermore, the tackled optimization objectives were the minimization of cost, weight and cost-weight simultaneously for designing regular or high strength concrete beams.
\end{abstract}

Keywords-Reinforced concrete beams, Metaheuristic algorithms, Harmony search, Multi-objective optimization

\section{INTRODUCTION}

C ost and weight minimization of products have been always the interest of many industries; RC structures, in the construction industry, is not an exception. The problem of designing reinforced concrete structures gained its complexity from the highly non-linear behavior of the constraints as well as the involved design equations. Add to that, the nature of the mixed discrete -continuous design variables involved in the designed cross sections. Indeed, this type of problem is widely known as sizing optimization problem with a fixed topology (refer to [1] for more details).

The design of reinforced concrete structures using optimization methods is relatively challenging compared to steel structures [2]. Providing designs that are fully detailed according to

\footnotetext{
${ }^{1} \bowtie$ The corresponding author
}

international manuals and recommendations, such as [3], [4], [5], [6], for reinforced concrete structures, is always defying the intelligence of metaheuristic algorithms and self-learning techniques. Essentially, such problems are always associated with a high number of dimensions (design variables).

Numerous publications handled the problem of designing reinforced concrete members either by using rules-of-thumb or the use of intelligent algorithms. Simplifications and assumptions were always the core of any successfully conducted optimization process.

One of the detailed studies in this branch was issued by Akin and Saka [2]. That study manipulated the design of detailed RC continuous beams per ACI318-05 code. The beam's width and depth had been used as independent design variables, reinforcement areas and the number of bars had been implemented as well. Cutoff bars per each span and support had been considered in the proposed model. The design was obtained by using the traditional harmony search algorithm [7]. Ultimate and serviceability states were included. Simplifications were made in calculating the lengths of compression/tension bars and hooks as well according to ACI315-02 detailing manual.

Another detailed paper published by Jahjouh et al. [8] demonstrated the design of $\mathrm{RC}$ continuous beams in details using a slightly modified Artificial Bee Colony (ABC) algorithm. They used ACI318-08 standards, the American code, in the design process. More independent design variables, compared to [2], had been used in that paper and meticulous bars detailing. Development lengths and anchorage, have been calculated as per the design equations provided by ACI31808. Moreover, a classical concept of optimization has been 
considered to enhance the $\mathrm{ABC}$ algorithm which is the modification of some of the design variables while keeping the others without modifications, and this is due to the complexity of the problem.

In the last decade, the significance of Building Information Modelling (BIM) software packages raised dramatically. In [9], the authors optimized structural reinforcement in three different folds using a BIM platform. In the first two folds, they optimized the compression and tension rebars separately, while the third one was used only for optimizing the distribution of shear reinforcement. In that paper, fixed rectangular crosssections had been provided, as inputs, to optimize rebars for beams and columns. Furthermore, BS8110 provisions, British standards, had been used and the problem was solved using the Hybrid Genetic Algorithm.

Govindaraj and Ramasamy [10], dealt with the problem of designing RC continuous beams according to the Indian Standards (IS code) using the Genetic Algorithm (GA) [11]. The only independent design variables were the depth and the width of the beam, while the others were taken as dependent variables.

Chutani and Singh [12] studied the design of RC structural members such as beams and columns as per the Indian Standard by using the enhanced Particle Swarm Optimization (PSO) algorithm. The paper's objective was to get the optimal cost of these structures. RC beams had been designed assuming that the independent design variables were the beam width and depth; other design parameters were calculated accordingly. Ultimate and serviceability limit states were considered in the design process.

Alqedra et al. [13] used the GA to find the optimal cost of the design of RC prestressed simple beams according to the American standards (ACI318-05). The design variables were namely: width of the beam, depth of the beam, number of flexural bars, diameters of flexural bars, number of tendons, and diameters of tendons, as well as the eccentricity of the tendons. The shear design had not been taken into consideration in that study. In 2006, both Kwok and Kong [14] carried out the design of common RC structures. Among these structures the design of $\mathrm{RC}$ prestressed beams used the GA. The dimensions of the concrete prestressed box girder were the design variables. Rules-of-thumb and simplifications from past experiences had been included. The design was accomplished by using the Hong Kong code of practice.

Many papers oversimplified the design problem of $\mathrm{RC}$ beams [15], [16], [17], [18], [19]. For instance, the design of doubly reinforced simply supported beams had been solved by both Adsul and Bhalchandra [19]. Ultimate and serviceability limit states had been considered using the GA according to the Indian Standards. In that paper, the design parameters were a bit different from other studies'. The beam width, tension reinforcement, compression reinforcement, and nominal cover were the independent design variables. In [15], the authors used the Artificial Neural Network (ANN) to design simple beams considering only the beam's width and effective depth as geometrical design variables and the number of bars besides the diameters for detailing according to the ACI318-08 code, while [18] used the GA for the design of simple RC beam according to the Eurocode 2. In [16], [17] used Bats Algorithm (BA) and Teaching-Learning-Based Optimization (TLBO) algorithm, respectively, for the sectional design of both singly and doubly reinforced beams according to the ACI318 design code. The design variables in those papers were the beam depth and width and compression/tension steel bars numbers and diameters.

More publications about this topic have been revealed in [20], where the authors reported the recent applications of heuristic and metaheuristic algorithms in designing RC structures.

Simplifications, in former studies, had always been used for non-critical, less sensitive parameters, as an attempt to reduce the total efforts required to solve a problem and to relax the computational complexity. These simplifications promoted the performance of state-of-the-art algorithms efficiently. In this paper, the optimization problem complexity has risen; new design variables have been introduced besides modifying some. Two new design variables have been added to optimize the location of the top and bottom flexural bars curtailments. Overall, three main objectives have been minimized separately or jointly in this paper under different design cases and various complexities to cover a wider range of practical design applications.

In the current work, based on harmony search [7], musicinspired algorithm, a newly modified algorithm, has been introduced as a solver for the beam's model. Specifically speaking, a slightly modified approach of the parametersetting-free harmony search (PSFHS) algorithm [21] has been used.

In short, this paper solves a wider range of design cases with different design situations, different boundary conditions, and materials according to the Eurocode 2 design norm. Moreover, it provides more detailed solutions with a modified self-adapting algorithm. This paper is organized into six different sections. Sections I and II cover an introduction to the relevant works and the used design norms respectively. Section III describes the modified approach of harmony search algorithm, while Section IV defines the mathematical relations of the problem (optimization model). Section $\mathrm{V}$ provides five different design cases with their detailed results. The conclusions have been drawn in Section VI Finally, three additional appendices have been added to cover the used flexural reinforcement design equations, a small-scale benchmarking and comprehensive results for the fourth case study.

\section{DESIGN OF REINFORCED CONCRETE BEAMS PER EUROCODE 2}

In this paper, the design of reinforced concrete has been addressed rigorously as per the Eurocode standards. The designs of bending, shear, deflection and shrinkage have been followed rigorously and calculated accordingly, refer to [22], [23] for more details. In Appendix A, equivalent equations to the strain compatibility approach, see [5], [6], [24], have been provided for effortless and straightforward evaluation of the bending capacity of a doubly reinforced section according to the Eurocode provisions. 


\section{MODIFIED PSFHS ALGORITHM}

Harmony search (HS) algorithm is a novel metaheuristic algorithm that was proposed first by Zong Woo Geem in 2001 (see [7]). The main inspiration behind this novel algorithm is the musicians' improvisation process. HS is a random-based search algorithm rather than being a gradient-based one. Harmony search is a non-nature-inspired algorithm or basically an artificially inspired algorithm (see [25] for definitions).

The main challenge, for metaheuristics, is always about developing new robust algorithms that are capable of solving complicated problems with better accuracy. Nevertheless, maintaining the number of iterations or time affordable and computationally available is needed. Harmony search has been successfully used in various applications related to scientific and engineering problems [26], where it functioned potentially better than many other well-known algorithms. Harmony search algorithm has played a role in a plethora of applications [27]; the pipe network design problem [28], structural optimization [2], [29], and many other engineering applications proving its robustness and superiority in continuous and discrete design problems.

\section{A. PSFHS algorithm mechanism}

Slight modifications have been imposed on the original parameter-setting-free harmony search algorithm as explained in the coming subsections. Referring to [7], [21], [30], [31], one can capture the main algorithm procedures and develop a concrete understanding of its derived mechanism. In the current work, the discussion will be focused on the proposed modifications, while the detailed process can be found in former pieces of literature.

In Section III-A1 and III-A2, the modifications will be elaborated, while Algorithm [1 defines the main steps of the described approach in this context.

1) Initialize harmony memory: As one of the populationbased algorithms, this stage is crucial for the overall behavior of the algorithm. This step has been modified to get potentially filtered design vectors (solution vectors) in the harmony memory matrix $[\mathrm{HM}]$. The initial $[\mathrm{HM}]_{\mathrm{HMS} \times \mathrm{N}}$, random tuning step [21], starts with a number of vectors equals to $\xi \mathrm{HMS} \times \mathrm{N}$, where the symbol $\xi$ is a positive integer multiplier. Afterward, the initial matrix is ranked and the best HMS design vectors, based on the fitness, can be chosen as the final [HM]. Another sampling option is by using Latin Hypercube Sampling (LHS). Using LHS will decrease the computational efforts and provide potentially better populations [32].

2) Rehearsal and performance steps: Both the rehearsal and performance steps are concretely dependent on HMCR and PAR probabilities. The occurrence probabilities of HMCR and PAR that were registered in successfully generated and replaced solution vectors redefine the current ones, HMCR and PAR, in the performance phase (refer to [21] for details). Those two steps are the core of the algorithm where the optimum balance between diversification and intensification processes must be guaranteed. The modifications implied on this part of the algorithm are the newly imposed limits on both HMCR and PAR calculated values. The modified equations are shown in (1) and (2). The process records are all maintained in the operation type matrix [OTM] (see (3)). Equations 4 and (5) record the histories of HMCR and PAR respectively. Note that the maximum number of iterations, including both the rehearsal and performance steps, is denoted by MaxItr for the hereafter.

$$
\begin{aligned}
& \operatorname{HMCR}_{j}^{i}=\frac{\operatorname{Count}\left(O^{j}=\text { Memory }\right)}{\mathrm{HMS}} \text {, where } \\
& \mathrm{HMCR}_{j}^{i} \in\left[\mathrm{HMCRi}, \mathrm{HMCR}_{\text {max }}\right] \\
& \operatorname{PAR}_{j}^{i}=\frac{\operatorname{Count}\left(O^{j}=\text { Pitch }\right)}{\mathrm{HMS}}, \text { where } \\
& \operatorname{PAR}_{j}^{i} \in\left[\mathrm{PAR}_{\text {min }}, \mathrm{PARi}\right]
\end{aligned}
$$

Those introduced limits will guarantee that the PSFHS will not block itself in any local minimum as well as lag the process from reaching a local optimum before getting the chance to inspect wider ranges of solution vectors leading to premature convergence. Recommended ranges for both HMCR and PAR are $[0.70,0.95]$ and $[0.20,0.50]$, respectively, as observed from [28], [29], [33]. Accordingly, applying such limits can considerably enhance the robustness of this method besides decreasing the variation of the results for different consecutive independent runs, i.e standard deviation. The new parameters $\mathrm{HMCR}_{\max }$ and $\mathrm{PAR}_{\min }$ have been introduced to bound the improvisation probabilities working ranges for each design variable. Consequently, HMCR and PAR probabilities will take the advantage of dynamically detecting the behavior of each design variable independently from others, while doing it in the most suitable range. $\mathrm{HMCR}_{\max }$ in this study is kept lower than the value of 1.0 by about 1.0 to $5.0 \%$, so basically $\mathrm{HMCR}_{\text {max }} \in[0.95,0.99]$, while $\mathrm{PAR}_{\text {min }} \in[0.05,0.1]$.

Elaborately, approaches based on metaheuristic are capable of finding good and sometimes optimal solutions to problem instances of realistic size [34], [35], where using stochastic combinatorial optimization always bears some uncertainty. In contrast, allowing HMCR and PAR to reach values of 1.0 and 0.0 , as can be observed in [21], clashes with the basic definition of metaheuristic algorithms. In other words, the diversification and the intensification processes are processes to sense the solution domain and finding a good balance between both processes [36], but not a process with guaranteed and certain aspects. Allowing both probabilities of 1.0 and 0.0 means that the behavior and the distribution of the problem are known to the algorithm at a certain point, which can be considered and described as a gradient-based approach rather than being a stochastic approach. Again, Algorithm 1, depicts a pseudo code for the detailed steps of the proposed and slightly modified approach of the PSFHS algorithm.

\section{Formulation OF THE RC DESIGN OPTIMIZATION MODEL}

A new optimization model has been proposed in this study for designing $\mathrm{RC}$ beams. The number of independent design variables has been increased, as well as a more rigorous approach has been used in evaluating objectives and constraints. Figure 1 and Table I explain the design variables that have 


$$
\begin{aligned}
& {[\mathrm{OTM}]=\left(\begin{array}{cccc}
O_{1}^{1}=\text { Random } & O_{2}^{1}=\text { Memory } & \ldots & O_{N}^{1}=\text { Memory } \\
O_{1}^{2}=\text { Pitch } & O_{2}^{2}=\text { Random } & \ldots & O_{N}^{2}=\text { Pitch } \\
\vdots & \ldots & \ddots & \vdots \\
O_{1}^{H M S}=\text { Pitch } & O_{2}^{H M S}=\text { Random } & \ldots & O_{N}^{H{ }^{M S}}=\text { Memory }
\end{array}\right)} \\
& {[\mathrm{HMCRH}]=\left(\begin{array}{cccc}
H M C R_{1}^{1} & H M C R_{2}^{1} & \ldots & H M C R_{N}^{1} \\
H M C R_{1}^{2} & H M C R_{2}^{2} & \ldots & H M C R_{N}^{2} \\
\vdots & \ldots & \ddots & \vdots \\
H M C R_{1}^{\text {MaxItr }} & H M C R_{2}^{\text {MaxItr }} & \ldots & H M C R_{N}^{\text {MaxItr }}
\end{array}\right)} \\
& {[\text { PARH }]=\left(\begin{array}{cccc}
P A R_{1}^{1} & P A R_{2}^{1} & \cdots & P A R_{N}^{1} \\
P A R_{1}^{2} & P A R_{2}^{2} & \cdots & P A R_{N}^{2} \\
\vdots & \cdots & \ddots & \vdots \\
P A R_{1}^{\text {MaxItr }} & P A R_{2}^{\text {MaxItr }} & \ldots & P A R_{N}^{\text {MaxItr }}
\end{array}\right)}
\end{aligned}
$$

been introduced in this paper, where the number of design variables is expressed in terms of the number of spans per beam $N_{\text {spans }}$.

The determination of design variables must occupy huge solicitude depending on many interfered or mutually-exclusive factors, for instance, the computational capacity, the robustness of the solver or the algorithm used, the total run-time, the variable sensitivity in the design problem and/or past experiences. In this study, the only dependent design variable is the distribution of the shear stirrups over spans; others have been treated as independent design variables.

It is important to mention that the explained design, dependent or independent, variables number can change according to the type of the provided boundary conditions and whether the problem is symmetric or not. Moreover, Fig. 2 explains how each design vector is stored, manipulated and accessed in the memory.

\section{A. Design objective functions}

Three objectives have been used in this study, namely cost minimization, weight minimization and simultaneous cost and weight minimization. The objective functions are shown in 6 to (8). Refer to [37] to find other possible methods to deal with multi-objectives problems.

$$
\operatorname{Min} . F_{c o s t}(\vec{X})=C_{\text {conc }} V_{\text {conc }}+C_{s t} W_{s t}+C_{f} A_{f}
$$

$$
\operatorname{Min} . F_{\text {weight }}(\vec{X})=W_{\text {conc }}+W_{\text {st }}
$$

Min. $F_{\text {cost } \& \text { weight }}(\vec{X})=\xi_{1} F_{\text {cost }}(\vec{X})+\xi_{2} F_{\text {weight }}(\vec{X})$ where,

$\vec{X}$ : the proposed design vector (see Fig. 2);

$A_{f}$ : area of formwork $\left[\mathrm{m}^{2}\right]$;

$C_{\text {conc }}:$ concrete cost per $\left[\mathrm{m}^{3}\right]$;

$C_{s t}:$ steel cost per $[\mathrm{kN}]$;

$C_{f}$ : formwork cost per $\left[\mathrm{m}^{2}\right]$;

$V_{\text {conc }}$ : concrete volume $\left[\mathrm{m}^{3}\right]$;

$W_{\text {conc }}$ : concrete weight $[\mathrm{kN}]$;

$W_{s t}:$ steel weight $[\mathrm{kN}]$;

$\xi_{1}$ : weighting factor for the cost objective;

$\xi_{2}$ : weighting factor for the weight objective.

The dynamic penalization method has been used for this constrained optimization problem. One preferable and common model for evaluating the fitness of any design vector is shown in 9 .

$$
\operatorname{Fitness}(\vec{X})=F(\vec{X})\left(1+\omega_{1} P_{T}\right)^{\omega_{2}}
$$

where,

$P_{T}$ : sum of all violations (penalties) (see (15));

$\omega_{1}$ : penalty function constant;

$\omega_{2}$ : penalty function exponent.

\section{B. Design constraints}

The problem is constrained to ensure that the composed solution vector has been chosen from a valid design pool according to the design norms. In this paper, the main beam constraints at the ultimate limit state (ULS) are the bending capacity, maximum shear force (for ductile shear failure), the maximum number of layers (spacings), and minimum and maximum area steel provided for both compression and tension steels. Considering the serviceability limit state (SLS), the 


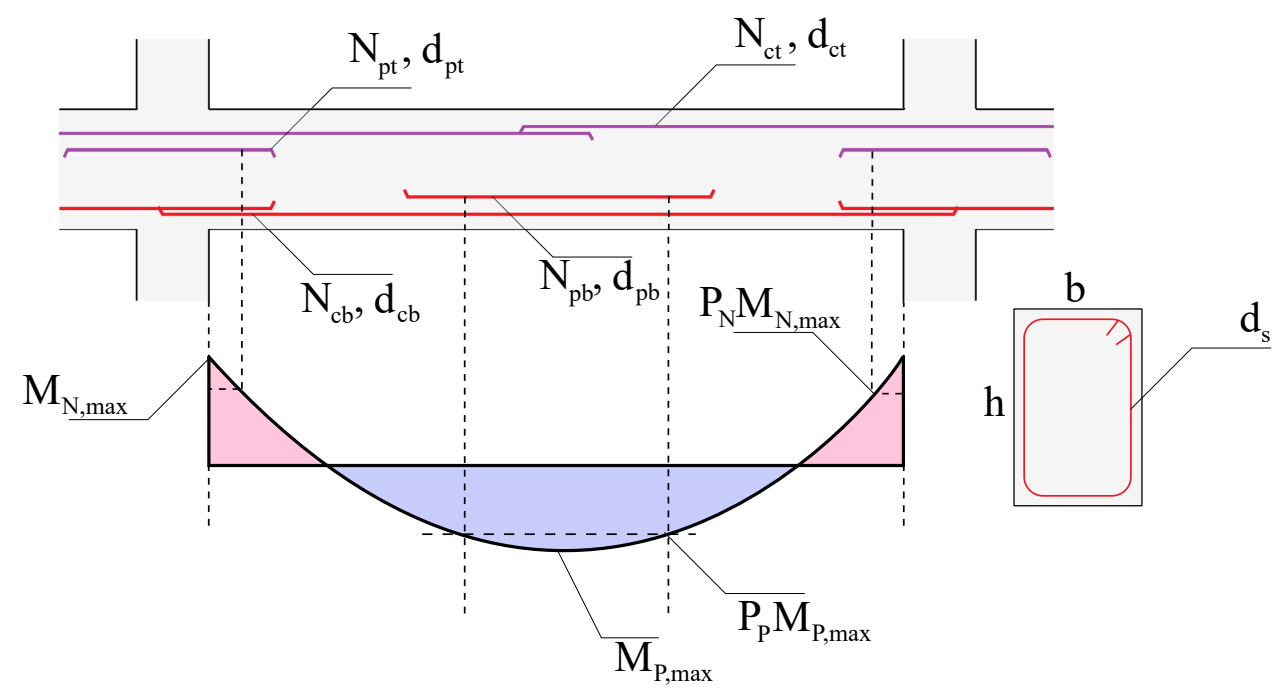

Fig. 1. Description of the model's design variables
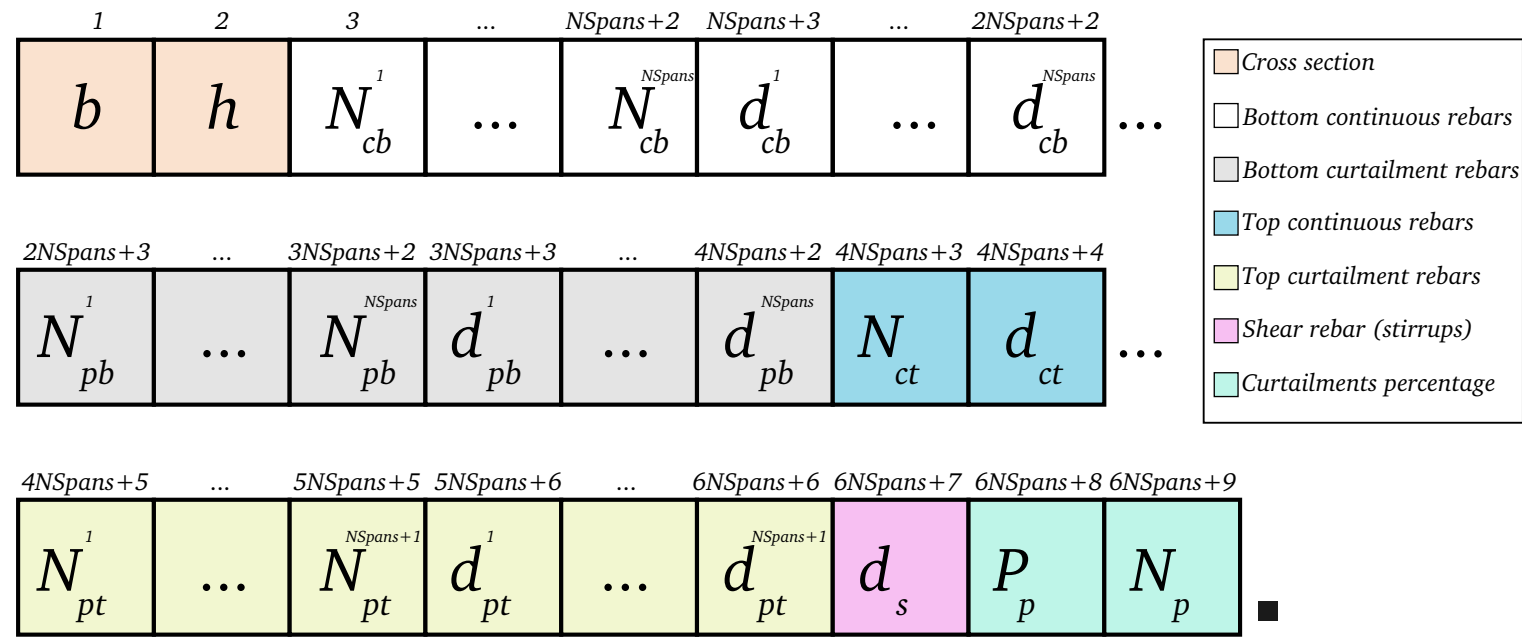

Fig. 2. Design vectors' template in the computer's memory

deflection of the beam due to long-term creep and shrinkage has been checked. For safeguarding against cracks, minimum requirements for tension steel area and spacings have been implicitly considered in the spacings control. The following points summarize the equations used to evaluate the fitness of each composed design vector:

1. Bending capacity $\left(M_{d}\right)$ penalty: to ensure that all crosssections are provided with enough resistance against the imposed ultimate bending actions $\left(M_{u}\right)$ :

$$
P_{1}= \begin{cases}\frac{\left|M_{u}\right|-M_{d}}{M_{d}} & ,\left|M_{u}\right|>M_{d} \\ 0 & , \text { otherwise. }\end{cases}
$$

2. Maximum and minimum area steels penalties: to ensure that the provided steel $\left(A_{s}\right)$ in tension is between maximum $\left(A_{s, \max }\right)$ and minimum $\left(A_{s, \min }\right)$ limits. While the provided compression steel is not over the maximum
$\left(A_{s, \max }\right)$ limit:

$$
P_{2}= \begin{cases}\frac{A_{s, \text { min }}-A_{s}}{A_{s, \min }} & , A_{s, \text { min }}>A_{s} \\ \frac{A_{s}-A_{s, \max }}{A_{s, \max }} & , A_{s, \max }<A_{s} \\ 0 & , \text { otherwise. }\end{cases}
$$

3. Maximum shear force capacity $\left(V_{R d, \max }\right)$ penalty: to ensure that the shear force $\left(V_{u}\right)$ will be resisted in the beam without crushing the concrete:

$$
P_{3}= \begin{cases}\frac{\left|V_{u}\right|-V_{R d, \max }}{V_{R d, \max }} & ,\left|V_{u}\right|>V_{R d, \max } \\ 0 & , \text { otherwise. }\end{cases}
$$

4. Maximum number of layers $\left(N_{\max }\right)$ penalty: the provided bars by the algorithm are arranged automatically according to a ranking-arranging algorithm. In this paper, the number of resulting layers $\left(N_{\text {layers }}\right)$ are considered instead of using the direct spacing calculation used by 


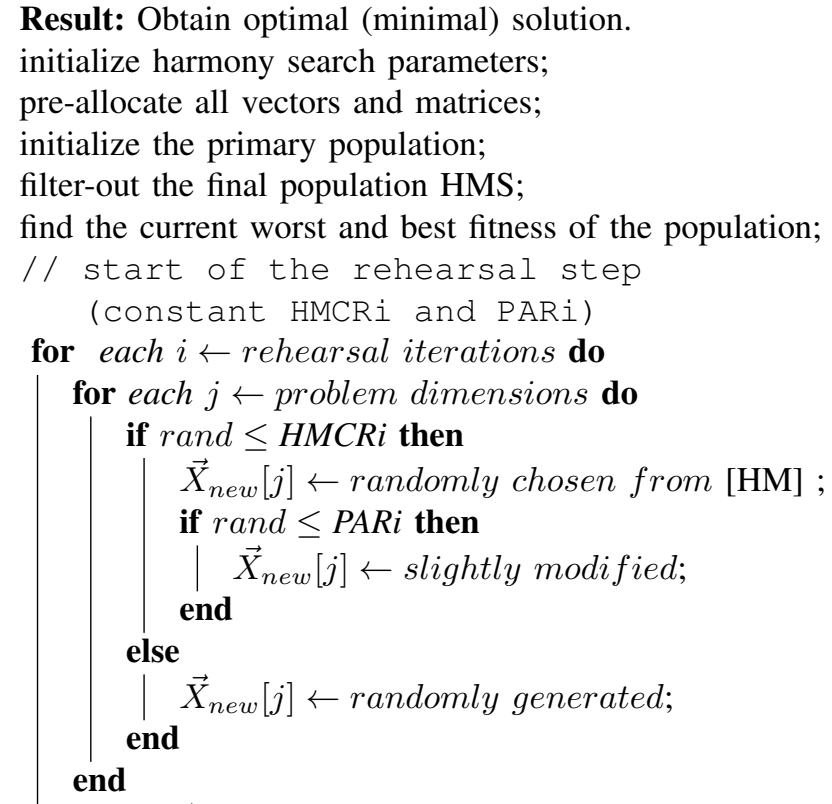

Result: Obtain optimal (minimal) solution.

initialize harmony search parameters;

pre-allocate all vectors and matrices;

initialize the primary population;

filter-out the final population HMS;

find the current worst and best fitness of the population;

// start of the rehearsal step
(constant HMCRi and PARi)

for each $i \leftarrow$ rehearsal iterations do

for each $j \leftarrow$ problem dimensions do

if rand $\leq H M C R i$ then

$\vec{X}_{\text {new }}[j] \leftarrow$ randomly chosen from $[\mathrm{HM}]$;

if rand $\leq P A R i$ then

$\vec{X}_{n e w}[j] \leftarrow$ slightly modified;

end

else

$\left.\right|_{\text {end }} \vec{X}_{n e w}[j] \leftarrow$ randomly generated;

end

check $\vec{X}_{\text {new }}$ limits;

evaluate the fitness $f\left(\vec{X}_{n e w}\right)$;

if $f\left(\vec{X}_{\text {new }}\right)<f\left(\vec{X}_{\text {worst }} \in[H M]\right)$ then

replace the worst design vector;

update worst and best solution vectors in [HM];

register the type of operations used to generate

each design variable in [OTM];

end

end

// start of the performance step (with

variable HMCR and PAR)

for each $i \leftarrow$ (MaxItr - rehearsal iterations $)$ do

for each $j \leftarrow$ problem dimensions do

evaluate $\mathrm{HMCR}_{j}^{i}$ and $\mathrm{PAR}_{j}^{i}$ according to the occurrence probabilities;

check the imposed limits on $\mathrm{HMCR}_{j}^{i}$ and $\operatorname{PAR}_{j}^{i}$;

if rand $\leq H M C R_{j}^{i}$ then

$$
\begin{aligned}
& \quad \vec{X}_{\text {new }}[j] \leftarrow \text { randomly chosen from }[\mathrm{HM}] ; \\
& \text { if rand } \leq P A R_{j}^{i} \text { then } \\
& \text { end } \vec{X}_{\text {new }}[j] \leftarrow \text { slightly modified; } \\
& \text { else } \\
& \text { end } \vec{X}_{\text {new }}[j] \leftarrow \text { randomly generated; }
\end{aligned}
$$

else

end

check $\vec{X}_{n e w}$ limits;

evaluate the fitness $f\left(\vec{X}_{n e w}\right)$;

if $f\left(\vec{X}_{n e w}\right)<f\left(\vec{X}_{\text {worst }} \in[H M]\right)$ then

replace the worst design vector;

update worst and best solution vectors in [HM];

register the type of operations used to generate

each design variable in [OTM];

end

end

Note 1: $f($.$) is the objective function or fitness.$

Note 2: this scheme is for minimization problems.

Algorithm 1: Modified Parameter-Setting-Free Harmony

Search Algorithm (PSFHS)
TABLE I

DETAILS OF THE MODEL'S DESIGN VARIABLES

\begin{tabular}{llll}
\hline Design variable & Unit & Number per beam & Notation \\
\hline Beam breadth & $\mathrm{mm}$ & 1 & $b$ \\
Beam depth & $\mathrm{mm}$ & 1 & $h$ \\
Number of continuous bottom bars & - & $N_{\text {spans }}$ & $N_{c b}$ \\
Diameter of continuous bottom bars & $\mathrm{mm}$ & $N_{\text {spans }}$ & $d_{c b}$ \\
Number of cutoff bottom bars & - & $N_{\text {spans }}$ & $N_{p b}$ \\
Diameter of cutoff bottom bars & $\mathrm{mm}$ & $N_{\text {spans }}$ & $d_{p b}$ \\
Number of continuous top bars & - & 1 & $N_{c t}$ \\
Diameter of continuous top bars & $\mathrm{mm}$ & 1 & $d_{c t}$ \\
Number of cutoff top bars & - & $N_{\text {spans }}+1$ & $N_{p t}$ \\
Diameter of cutoff top bars & $\mathrm{mm}$ & $N_{\text {spans }}+1$ & $d_{p t}$ \\
Diameter of shear reinforcement & $\mathrm{mm}$ & 1 & $d_{s}$ \\
Percent of positive bending cutoff bars & $\%$ & 1 & $P_{p}$ \\
Percent of negative bending cutoff bars & $\%$ & 1 & $N_{p}$ \\
\hline Total number of design variables & & $6 N_{\text {spans }}+9$ &
\end{tabular}

former pieces of literature such as [8]:

$$
P_{4}= \begin{cases}\frac{N_{\text {layers }}-N_{\max }}{N_{\max }} & , N_{\text {layers }}>N_{\max } \\ 0 & , \text { otherwise }\end{cases}
$$

5. Real deflection $\left(\delta_{\text {real }}\right)$ penalty: ensures that the deflection is within the Eurocode provisions $\left(\delta_{\max }\right)$; covers the intended use of the structure due to quasi-permanent actions. Notably, long-term creep and shrinkage effects have been considered and added to the actions' effect.

$$
P_{5}= \begin{cases}\frac{\left|\delta_{\text {real }}\right|-\delta_{\max }}{\delta_{\max }} & , \delta_{\text {real }}>\delta_{\max } \\ 0 & , \text { otherwise. }\end{cases}
$$

Afterward, the final violations (penalties) of each design vector are evaluated (See (15)).

$$
P_{T}=\sum_{i=1}^{5} P_{i}
$$

\section{DESIGN CASES AND RESULTS}

In the present paper, five design cases with different objectives, geometries, material properties, and boundary conditions have been solved. Table $\Pi$ reveals the working ranges considered for solving the proposed design cases.

\section{A. Design case (1)}

The first design case considered in this study is a five-span symmetric beam with the related loading shown in Fig. 3 . The algorithm's input data is listed in Table III.

The problem has been solved according to the formerly explained design variables with a symmetrified condition. In this case, the size of the design pool is $3.592 \times 10^{+24}$, considering only 25 design variables, rather than solving the whole beam for $2.4212 \times 10^{+34}$ design options with 35 independent design variables. A total of 30,000 iterations have been used to converge the best solution according to the proposed algorithm.

Table IV] summarizes the results of 10 independent runs for minimizing the weight of the beam; the best result achieved 
TABLE II

DESIGN VARIABLES AND SPECIFIED WORKING RANGES FOR THE DESIGN POOL

\begin{tabular}{lllll}
\hline Design variable & Unit & Number per beam & Variables range & Step size \\
\hline Beam breadth & $\mathrm{mm}$ & 1 & $250 \rightarrow 1,800$ & 50 \\
Beam depth & $\mathrm{mm}$ & 1 & $250 \rightarrow 1,000$ & 50 \\
Number of continuous bottom bars & - & $N_{\text {spans }}$ & $2 \rightarrow 15$ & 1 \\
Diameter of continuous bottom bars & $\mathrm{mm}$ & $N_{\text {spans }}$ & $10 \rightarrow 20$ & 2 \\
Number of cutoff bottom bars & - & $N_{\text {spans }}$ & $0 \rightarrow 15$ & 1 \\
Diameter of cutoff bottom bars & $\mathrm{mm}$ & $N_{\text {spans }}$ & $10 \rightarrow 20$ & 2 \\
Number of continuous top bars & - & 1 & $2 \rightarrow 15$ & 1 \\
Diameter of continuous top bars & $\mathrm{mm}$ & 1 & $10 \rightarrow 20$ & 2 \\
Number of cutoff top bars & - & $N_{\text {spans }}+1$ & $0 \rightarrow 15$ & 1 \\
Diameter of cutoff top bars & $\mathrm{mm}$ & $N_{\text {spans }}+1$ & $10 \rightarrow 20$ & 2 \\
Diameter of shear reinforcement & $\mathrm{mm}$ & 1 & $8 \rightarrow 12$ & 2 \\
Percent of positive bending cutoff bars & $\%$ & 1 & $0.0 \rightarrow 1.0$ & 0.05 \\
Percent of negative bending cutoff bars & $\%$ & 1 & $0.0 \rightarrow 1.0$ & 0.05 \\
\hline Total number of design variables & \multicolumn{5}{c}{$6 N_{\text {spans }}+9$} & & \\
\hline
\end{tabular}

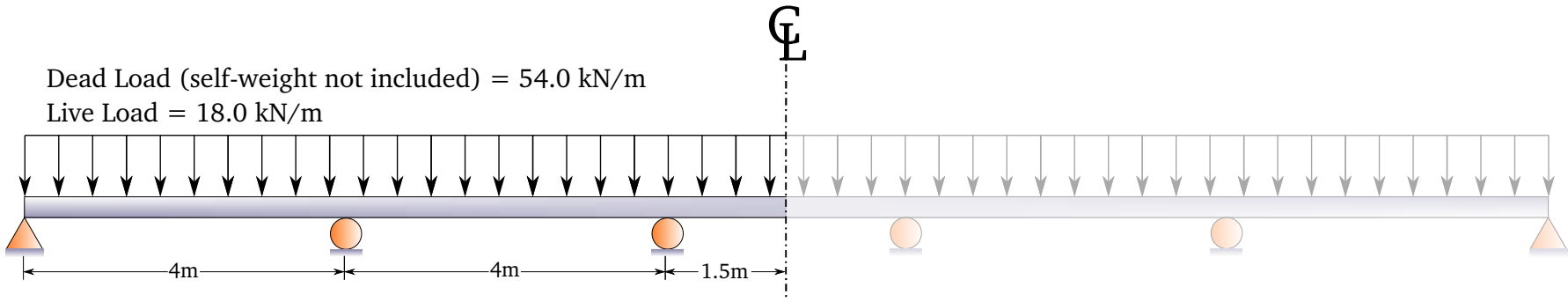

Fig. 3. Design case (1) - geometry and loading

TABLE III

ALGORITHM'S INPUT VALUES FOR DESIGN CASES $(1) \rightarrow(3)$

\begin{tabular}{ll}
\hline The property & Value \\
\hline$f_{c k}[\mathrm{MPa}]$ & 30 \\
$f_{y k}[\mathrm{MPa}]$ & 500 \\
Max. aggregate size $[\mathrm{mm}]$ & 20 \\
Support width [mm] & 300 \\
Cement type & Normal hardening \\
Max. $N_{\text {layers }}$ & 2 \\
Relative humidity & $50 \%$ \\
Age of concrete at the & 7 \\
time of loading [Days] & Span length [mm] \\
Deflection limit [mm] & $\frac{250}{}$ \\
\hline
\end{tabular}

TABLE IV

DESIGN CASE (1) - SUMMARY OF 10 INDEPENDENT RUNS

\begin{tabular}{llll}
\hline Run No. & $\begin{array}{l}\text { Best weight } \\
{[\mathrm{kN}]}\end{array}$ & Run No. & $\begin{array}{l}\text { Best weight } \\
{[\mathrm{kN}]}\end{array}$ \\
\hline 1 & 42.125 & 6 & 42.542 \\
2 & 42.198 & 7 & 42.582 \\
3 & 42.286 & 8 & 42.286 \\
4 & 42.378 & 9 & 42.835 \\
5 & 42.477 & 10 & 47.860 \\
\hline
\end{tabular}

was $42.125 \mathrm{kN}$, and the weight summary of 10 different runs was $42.957 \pm 1.734 \mathrm{kN}$.

The details of reinforcement for the best run obtained are shown in Fig. 4. Shear reinforcement spacings along the beam are described in Table $\mathrm{V}$, while the convergence curve is illustrated in Fig. 5(a)
TABLE V

DESIGN CASE (1) - BEST RUN STIRRUPS DISTRIBUTION

\begin{tabular}{ll}
\hline Span No. & $\begin{array}{l}\text { Span reinforcement regions }[\mathrm{m}] \\
{[\text { Left, Middle, Right] of span }}\end{array}$ \\
\hline 1 & {$[1.05,0.70,2.10]$} \\
2 & {$[1.55,0.70,1.60]$} \\
3 & {$[0.95,0.70,1.20]$} \\
4 & {$[1.25,0.70,1.90]$} \\
5 & {$[1.85,0.70,1.30]$} \\
$*$ & Numbering starts from the left span to the right span. \\
$* *$ & The regions where the stirrups spacings are distributed.
\end{tabular}

It should be mentioned that the algorithm found the best solution where the cutoffs for positive bending moments are zero (only continuous bottom reinforcement provided). On the other hand, the top reinforcement was placed at $55 \%$ from the maximum negative bending corresponding at the face of the support, and as a result, the longitudinal bars' lengths developed accordingly.

\section{B. Design case (2)}

In the second design case, the cost of a four-span beam has been minimized (see Fig. 6). The costs of concrete, steel rebars, and formwork have been included in the objective. The used cost multipliers were: $105 \mathrm{USD} / \mathrm{m}^{3}$ for concrete, $90 \mathrm{USD} / \mathrm{kN}$ for the steel reinforcement and $92 \mathrm{USD} / \mathrm{m}^{2}$ for the formwork. In this design case, 33 independent design variables have been involved. As a consequence, this resulted in $2.780 \times 10^{30}$ valid design options; 80, 000 iterations were found to be satisfactory. 


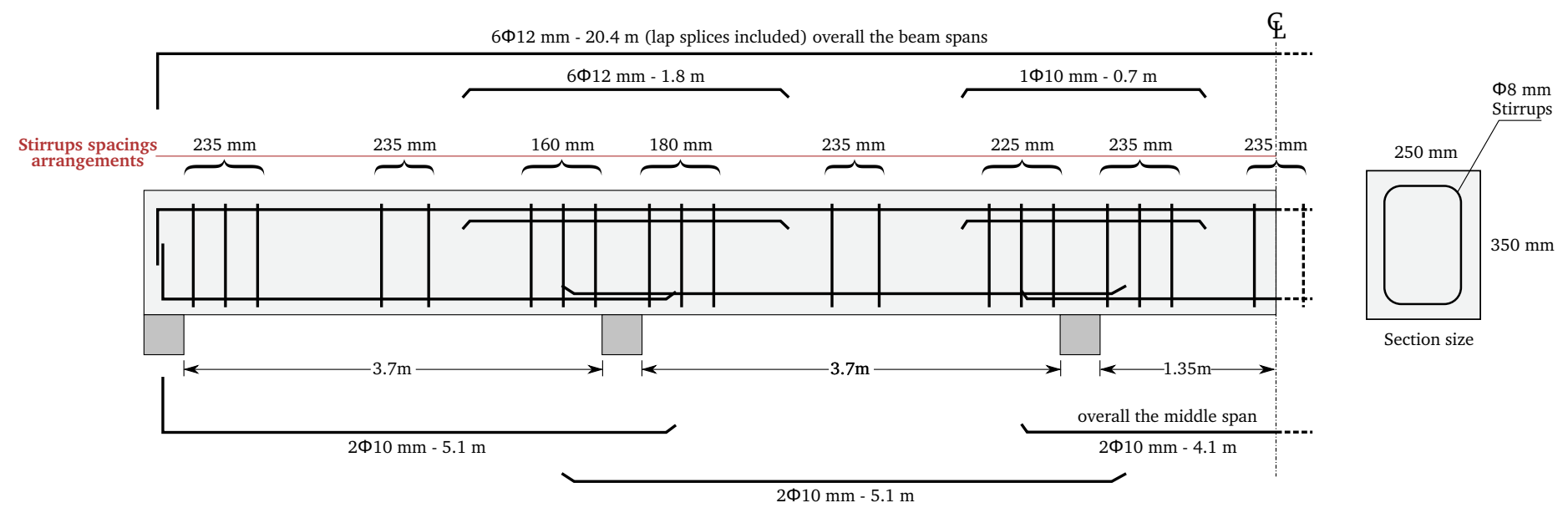

Fig. 4. Design case (1) - best run reinforcement details

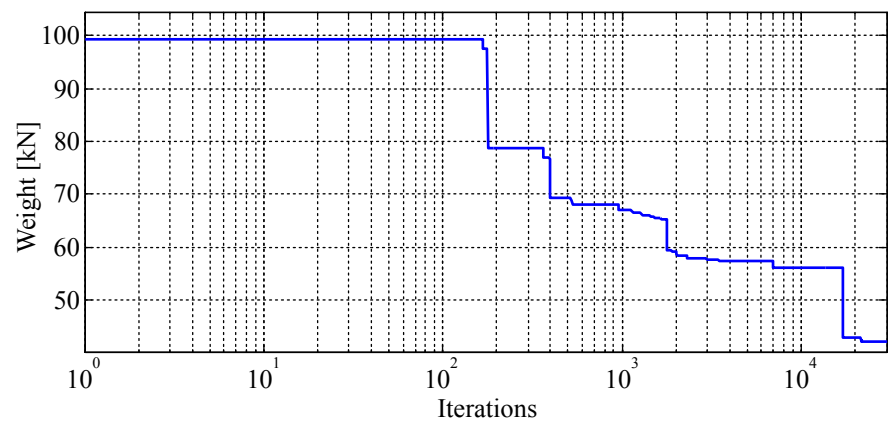

(a) Design case (1)

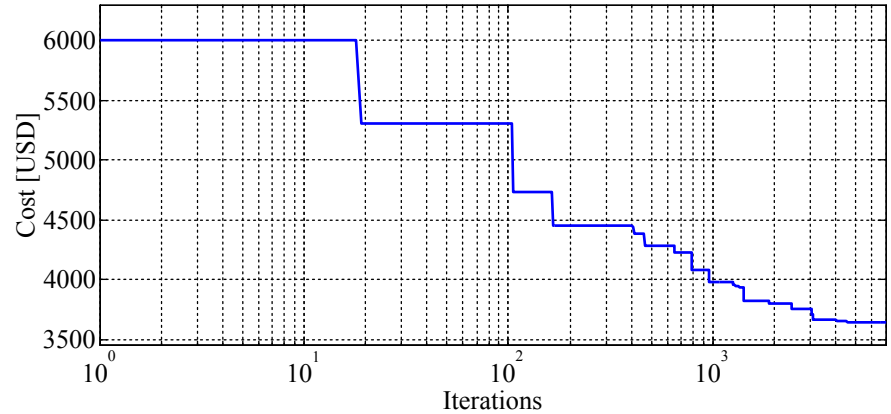

(c) Design case (3)

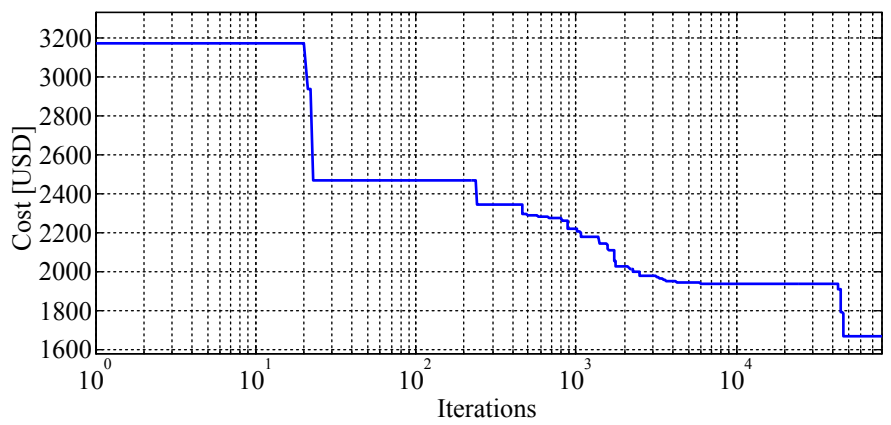

(b) Design case (2)

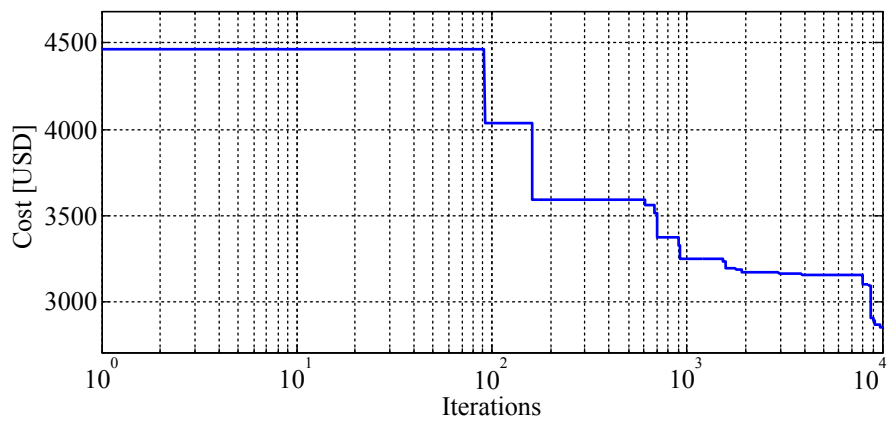

(d) Design case (4)

Fig. 5. Design cases (1) $\rightarrow$ (4) - best runs convergence curves

The results of 10 trials to solve the problem were reported at Table $\mathrm{VI}$ with an average and a standard deviation of $1,703.711 \pm 45.413$ USD. The best cost achieved was $1,663.641$ USD with an overall weight of $32.402 \mathrm{kN}$.

The obtained design details are revealed in Fig7 and the shear stirrups' regions are explained in Table VII The convergence of the best run is shown in Fig 5(b) The solution implies that cutoffs of the top reinforcement took place at $65 \%$ of the maximum moment at the face of the support and no cutoffs are considered for the bottom reinforcement. In this case, heavier top reinforcement means that the algorithm depends on increasing the ductility and reducing the deflection effects by providing top reinforcement for the beam.
TABLE VI

DESIGN CASE (2) - SUMMARY OF 10 INDEPENDENT RUNS

\begin{tabular}{llll}
\hline Run No. & $\begin{array}{l}\text { Best cost } \\
\text { [USD] }\end{array}$ & Run No. & $\begin{array}{l}\text { Best cost } \\
\text { [USD] }\end{array}$ \\
\hline 1 & $1,663.641$ & 6 & $1,686.698$ \\
2 & $1,677.991$ & 7 & $1,686.699$ \\
3 & $1,678.722$ & 8 & $1,696.313$ \\
4 & $1,684.416$ & 9 & $1,781.636$ \\
5 & $1,686.257$ & 10 & $1,794.743$ \\
\hline
\end{tabular}

\section{Design case (3)}

In this design case, cost minimization of a relatively longspan beam has been considered (refer to Fig. 8). With 17 
Dead Load (self-weight not included) $=27.0 \mathrm{kN} / \mathrm{m}$

Live Load $=9.0 \mathrm{kN} / \mathrm{m}$

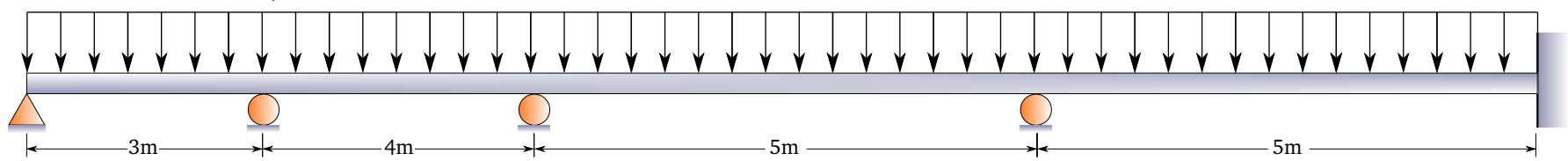

Fig. 6. Design case (2) - geometry and loading

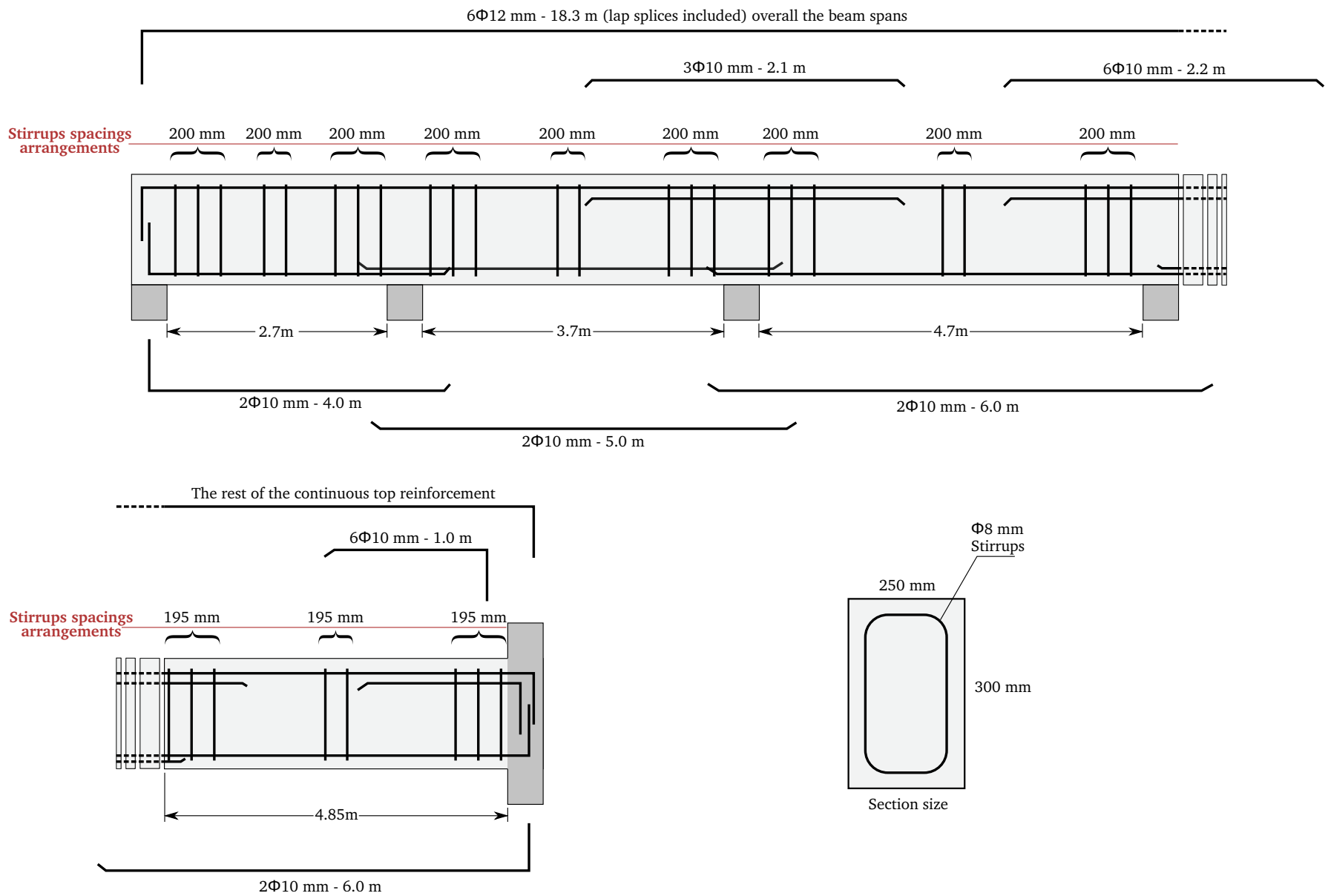

Fig. 7. Design case (2) - best run reinforcement details

TABLE VII

DESIGN CASE (2) - BEST RUN STIRRUPS DISTRIBUTION

\begin{tabular}{ll}
\hline Span No. & $\begin{array}{l}\text { Span reinforcement regions }[\mathrm{m}] \\
{[\text { Left, Middle, Right] of span }}\end{array}$ \\
\hline 1 & {$[0.35,1.30,1.20]$} \\
2 & {$[1.05,1.30,1.50]$} \\
3 & {$[1.55,1.30,2.00]$} \\
4 & {$[1.55,1.20,2.10]$} \\
\hline$*$ & Numbering starts from the left span to the right span. \\
$* *$ & The regions where the stirrups spacings are distributed. \\
\hline
\end{tabular}

independent design variables, constituting a design pool of $4.833 \times 10^{16}$ possible beams, 7,000 iterations were satisfactory for getting a reliable convergence through all the runs.

Using the same cost multipliers as in design case (2), the best cost obtained among 10 different runs was $3,643.179$ USD, and for the overall runs was $3,740.281 \pm$ 40.70 USD (see Table VIII). The details of the best run are shown in Fig. 9

The shear regions are explained in Table $\mathrm{IX}$ and Fig. 5(c) shows the convergence curve. Only top curtailments at $25 \%$, of the negative bending, have been assigned by the algorithm in this case.

\section{Design case (4)}

The use of high-strength concrete (HSC) acquired a great importance in the recent applications of reinforced concrete 
Dead Load (self-weight not included) $=54.0 \mathrm{kN} / \mathrm{m}$

Live Load $=18.0 \mathrm{kN} / \mathrm{m}$

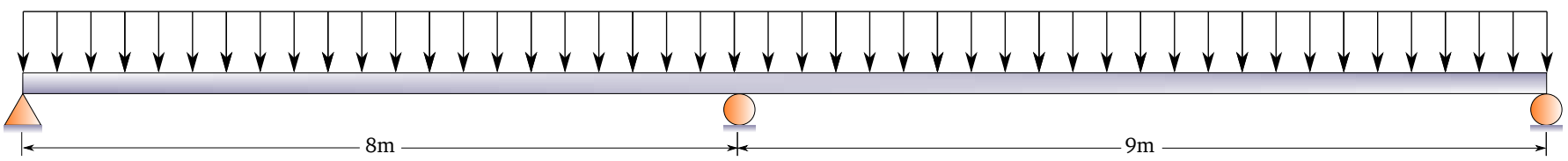

Fig. 8. Design case (3) - geometry and loading

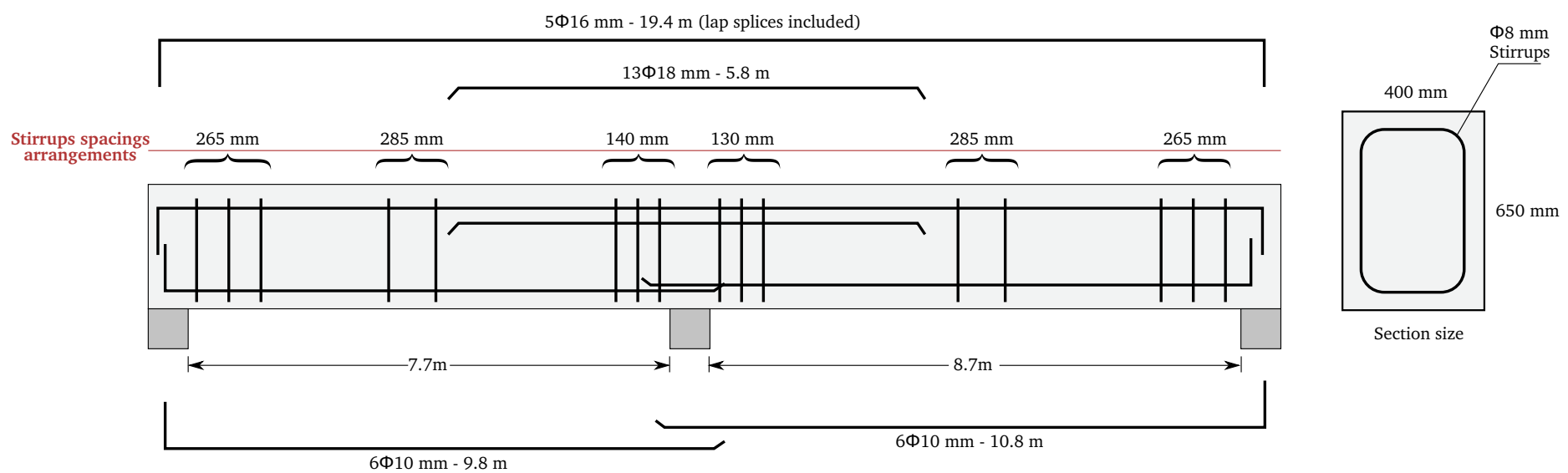

Fig. 9. Design case (3) - best run reinforcement details

TABLE VIII

DESIGN CASE (3) - SUMMARY OF 10 INDEPENDENT RUNS

\begin{tabular}{llll}
\hline Run No. & $\begin{array}{l}\text { Best cost } \\
\text { [USD] }\end{array}$ & Run No. & $\begin{array}{l}\text { Best cost } \\
\text { [USD] }\end{array}$ \\
\hline 1 & $3,643.179$ & 6 & $3,760.891$ \\
2 & $3,695.710$ & 7 & $3,761.673$ \\
3 & $3,730.161$ & 8 & $3,762.023$ \\
4 & $3,757.684$ & 9 & $3,762.780$ \\
5 & $3,758.532$ & 10 & $3,770.179$ \\
\hline
\end{tabular}

TABLE IX

DESIGN CASE (3) - BEST RUN STIRRUPS DISTRIBUTION

\begin{tabular}{ll}
\hline Span No. & $\begin{array}{l}\text { Span reinforcement regions [m] } \\
\text { [Left, Middle, Right] of span }\end{array}$ \\
\hline 1 & {$[1.95,1.70,4.20]$} \\
2 & {$[4.25,1.80,2.80]$} \\
\hline$*$ Numbering starts from the left span to the right span. \\
$*$ The regions where the stirrups spacings are distributed. \\
\hline
\end{tabular}

structures. For this reason, a relatively long span and heavily loaded beam (refer to Fig. 10, has been considered using high-strength concrete with more restrictions on the deflection limits. The algorithm's inputs have been changed for this case, and the case after (see Table $\mathrm{X}$.

Regarding the cost multipliers, the same multipliers have been used for steel and formwork in the earlier cases; HSC concrete cost multiplier is $285 \mathrm{USD} / \mathrm{m}^{3}$ for this case. This example has been solved for the three objectives (see (6) to
TABLE X

AlgORITHM'S INPUT VALUES FOR DESIGN CASES $(4) \rightarrow(5)$

\begin{tabular}{ll}
\hline The property & Value \\
\hline$f_{c k}[\mathrm{MPa}]$ & 55 \\
$f_{y k}[\mathrm{MPa}]$ & 500 \\
Max. aggregate size $[\mathrm{mm}]$ & 20 \\
Support width [mm] & 300 \\
Cement type & Normal hardening \\
Max. $N_{\text {layers }}$ & 2 \\
Relative humidity & $50 \%$ \\
Age of concrete at the & \\
time of loading [Days] & 7 \\
Deflection limit [mm] & Span length [mm] \\
& \\
\hline
\end{tabular}

(8)). With 23 design variables, a design pool of $3.741 \times 10^{22}$ options must be utilized to find a sufficiently good, near optimal, solution for each objective.

The best cost resulting from minimizing only costs was $2,853.337$ USD, with a weight of $51.104 \mathrm{kN}$. The overall result of the cost minimization process was $3,010.424$ \pm 68.165 USD. Taking into consideration only the weight objective, the best achieved weight was $51.329 \mathrm{kN}$, with a corresponding cost of 2,881.312 USD. The accuracy of the runs related to the weight minimization process was $66.450 \pm 6.368 \mathrm{kN}$.

Considering the process of minimizing both the costs and the weight, appropriate weighting factors have been chosen. In this particular case, it has been considered that the reduction 
Dead Load (self-weight not included) $=54.0 \mathrm{kN} / \mathrm{m}$

Live Load $=18.0 \mathrm{kN} / \mathrm{m}$

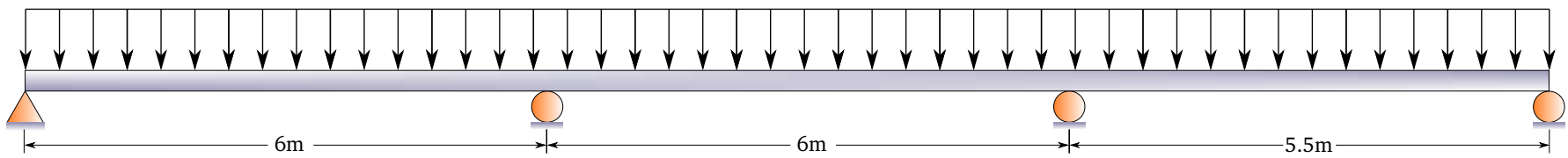

Fig. 10. Design case (4) - geometry and loading

TABLE XI

DESIGN CASE (4) - COST SUMMARY OF 10 INDEPENDENT RUNS

\begin{tabular}{llll}
\hline Run No. & $\begin{array}{l}\text { Best cost } \\
{[\text { USD] }}\end{array}$ & Run No. & $\begin{array}{l}\text { Best cost } \\
\text { [USD] }\end{array}$ \\
\hline 1 & $2,853.337$ & 6 & $3,019.378$ \\
2 & $2,961.527$ & 7 & $3,024.328$ \\
3 & $2,999.365$ & 8 & $3,066.457$ \\
4 & $3,003.584$ & 9 & $3,079.578$ \\
5 & $3,006.447$ & 10 & $3,090.240$ \\
\hline
\end{tabular}

TABLE XII

DESIGN CASE (4) - WEIGHT SUMMARY OF 10 INDEPENDENT RUNS

\begin{tabular}{llll}
\hline Run No. & $\begin{array}{l}\text { Best weight } \\
{[\mathrm{kN}]}\end{array}$ & Run No. & $\begin{array}{l}\text { Best weight } \\
{[\mathrm{kN}]}\end{array}$ \\
\hline 1 & 51.329 & 6 & 70.693 \\
2 & 62.753 & 7 & 70.750 \\
3 & 63.218 & 8 & 70.851 \\
4 & 63.557 & 9 & 70.312 \\
5 & 70.607 & 10 & 70.431 \\
\hline
\end{tabular}

of weight is as twice as the importance of minimizing the cost of the beam. In other words, the weighting factors have been chosen to be 2.0 for the weight objective and 1.0 for the cost objective. The best-obtained result in this process was $2,963.560$ USD $(62.576 \mathrm{kN})$. The overall result of all runs was $3,081.343 \pm 41.925$ USD $(69.586 \pm 2.464 \mathrm{kN})$. Tables XI XII, and XIII summarize the results of the 30 runs.

The details of the best cost obtained are revealed in Fig. 11 , while the convergence is shown in Fig. 5(d). It must be noted that in this case bottom and top cutoffs have been considered to control the deflection in the mid-span areas. The detailed bending, shear, and deflection results can be found in Fig. C.1

TABLE XIII

DESIGN CASE (4) - COST-WEIGHT SUMMARY OF 10 INDEPENDENT RUNS

\begin{tabular}{llll}
\hline Run No. & $\begin{array}{l}\text { Best cost[USD] } \\
\text { \& weight[kN] }\end{array}$ & Run No. & $\begin{array}{l}\text { Best cost[USD] } \\
\text { \& weight[kN] }\end{array}$ \\
\hline 1 & $2,963.560$ & 6 & $3,092.534$ \\
& 62.576 & & 70.349 \\
2 & $3,083.275$ & 7 & $3,095.399$ \\
& 70.275 & & 70.372 \\
3 & $3,089.550$ & 8 & $3,098.302$ \\
& 70.325 & & 70.396 \\
4 & $3,091.271$ & 9 & $3,102.098$ \\
& 70.339 & & 70.426 \\
5 & $3,090.602$ & 10 & $3,106.837$ \\
& 70.334 & & 70.464 \\
\hline
\end{tabular}

TABLE XIV

DESIGN CASE (4) - BEST RUN STIRRUPS DISTRIBUTION

\begin{tabular}{|c|c|c|c|}
\hline Span No. & \multicolumn{3}{|c|}{$\begin{array}{l}\text { Span reinforcement regions [m] } \\
\text { [Left, Middle, Right] of span }\end{array}$} \\
\hline $\begin{array}{l}1 \\
2 \\
3\end{array}$ & \multicolumn{3}{|c|}{$\begin{array}{l}{[1.65,1.10,3.10]} \\
{[2.25,1.10,2.50]} \\
{[2.45,1.10,1.80]}\end{array}$} \\
\hline \multicolumn{4}{|c|}{$\begin{array}{l}\text { * Numbering starts from the left span to the right } \\
\text { ** The regions where the stirrups spacings are distr }\end{array}$} \\
\hline \multicolumn{4}{|c|}{$\begin{array}{c}\text { TABLE XV } \\
\text { DESIGN CASE (5) - SUMMARY OF } 10 \text { INDEPI }\end{array}$} \\
\hline Run No. & $\begin{array}{l}\text { Best cost } \\
\text { [USD] }\end{array}$ & Run No. & $\begin{array}{l}\text { Best cost } \\
\text { [USD] }\end{array}$ \\
\hline 1 & $1,988.424$ & 6 & $2,096.992$ \\
\hline 2 & $2,076.559$ & 7 & $2,108.725$ \\
\hline 3 & $2,085.080$ & 8 & $2,108.808$ \\
\hline 4 & $2,086.283$ & 9 & $2,217.600$ \\
\hline 5 & $2,095.076$ & 10 & $2,182.089$ \\
\hline
\end{tabular}

and Table C.1 Detailed shear regions were explained in Table XIV

\section{E. Design case (5)}

By adopting the same inputs and cost multipliers used for the previous design case, the beam shown in Fig. 12 has been solved for the cost function only. This cantilever-end beam has 21 design variables that compile a domain of $3.897 \times 10^{20}$ possible design options. A total of 8,000 iterations were used to attain a sound stable and reliable solution during the cost minimization process.

The best cost obtained for this case was 1,988.424 USD $(34.381 \mathrm{kN})$, while the overall result for the 10 independent runs, Table XV, obtained was $2,104.564 \pm 61.424$ USD. The reinforcement details are shown in Fig. 13 and shear reinforcement regions are shown in Table XVI

Form Fig. 13 it can be seen that cutoffs were only considered for the bottom reinforcement of the first span (from the left).

The convergence curve revealed in Fig. 14 as well as HMCR and PAR histories for the design variables; calculated according to (1) and (2) and stored in (4) and (5). 


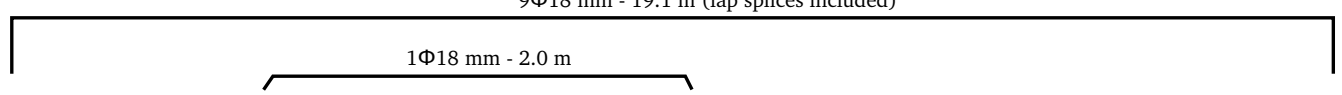

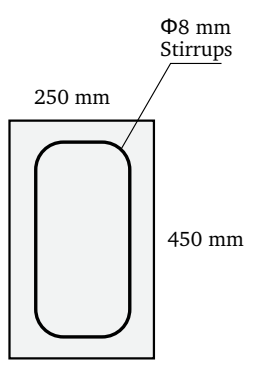

Section size

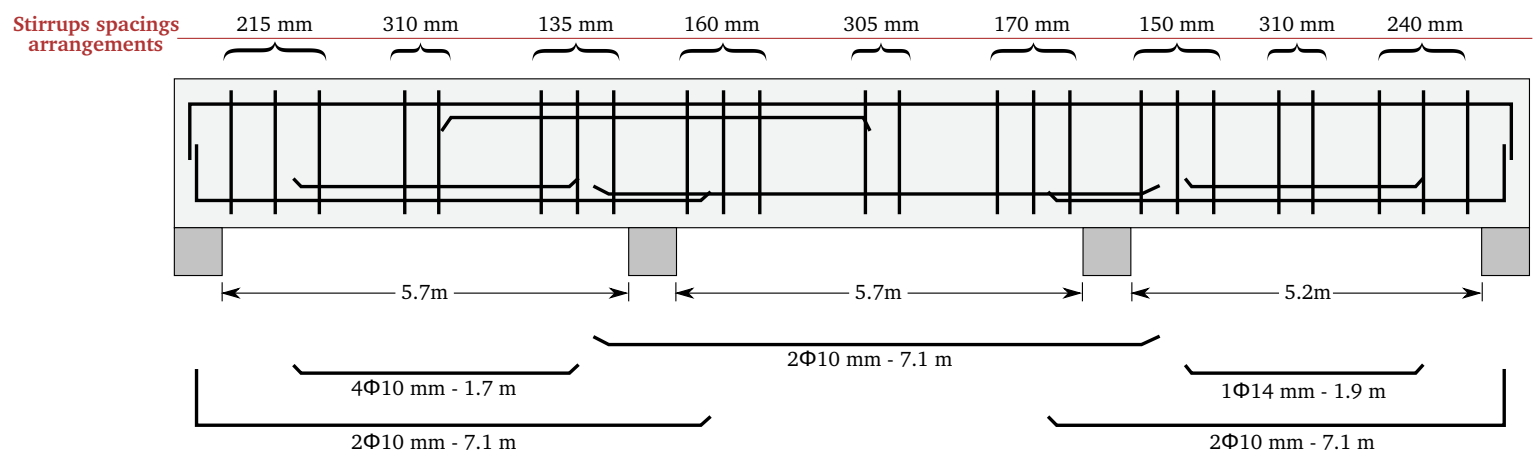

Fig. 11. Design case (4) - best run reinforcement details

Dead Load (self-weight not included) $=54.0 \mathrm{kN} / \mathrm{m}$

Live Load $=18.0 \mathrm{kN} / \mathrm{m}$

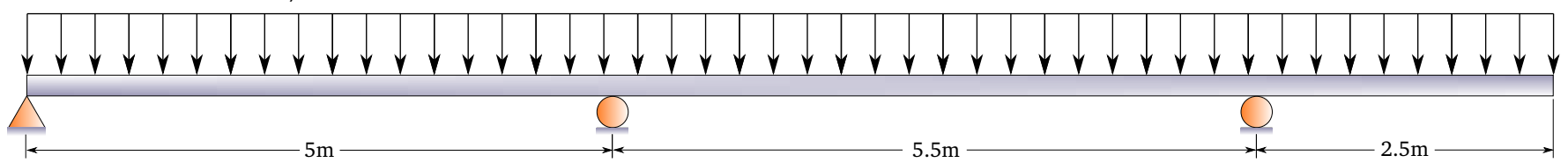

Fig. 12. Design case (5) - geometry and loading

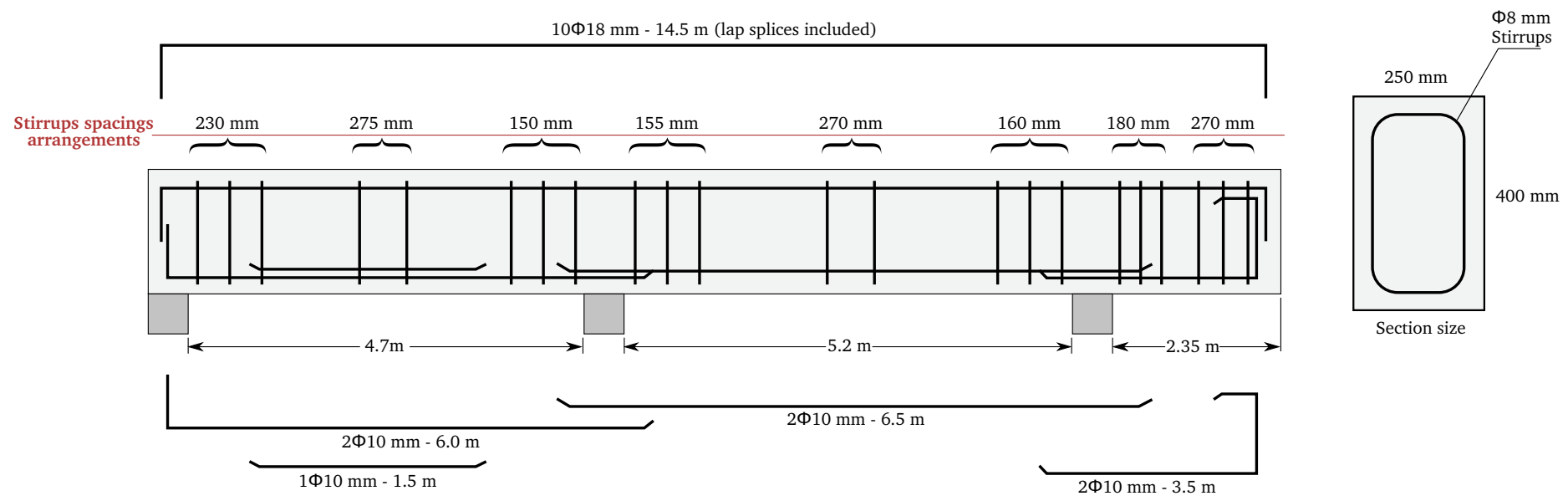

Fig. 13. Design case (5) - best run reinforcement details

\section{F. Response correlations}

One crucial factor that all metaheuristic algorithms have in common is the number of iterations (trials) used to solve problems. Indeed it is hard to tell whether these algorithms will respond the same under different conditions and objectives. In this paper, the number of involved design variables, $\boldsymbol{\Psi}$, as well as the size of the design pool, $\Omega$, have been considered to find a recommended and stable number of iterations to solve this specific problem. The first correlation, fitting the former design cases data, takes only the size of the design pool into account (refer to (16)).
MaxItr $=152 \Omega^{0.08946}$, where $R^{2}=0.9783$

Using only the number of involved design variables or the pool size does not reflect the real hardness of the problem, especially considering discrete problems where a finite number of solutions exists in the allowed bandwidth for each design variable. Equation (17) and the corresponding Fig. 15 reveal the interaction between $\boldsymbol{\Psi}, \boldsymbol{\Omega}$ and the stable number of 

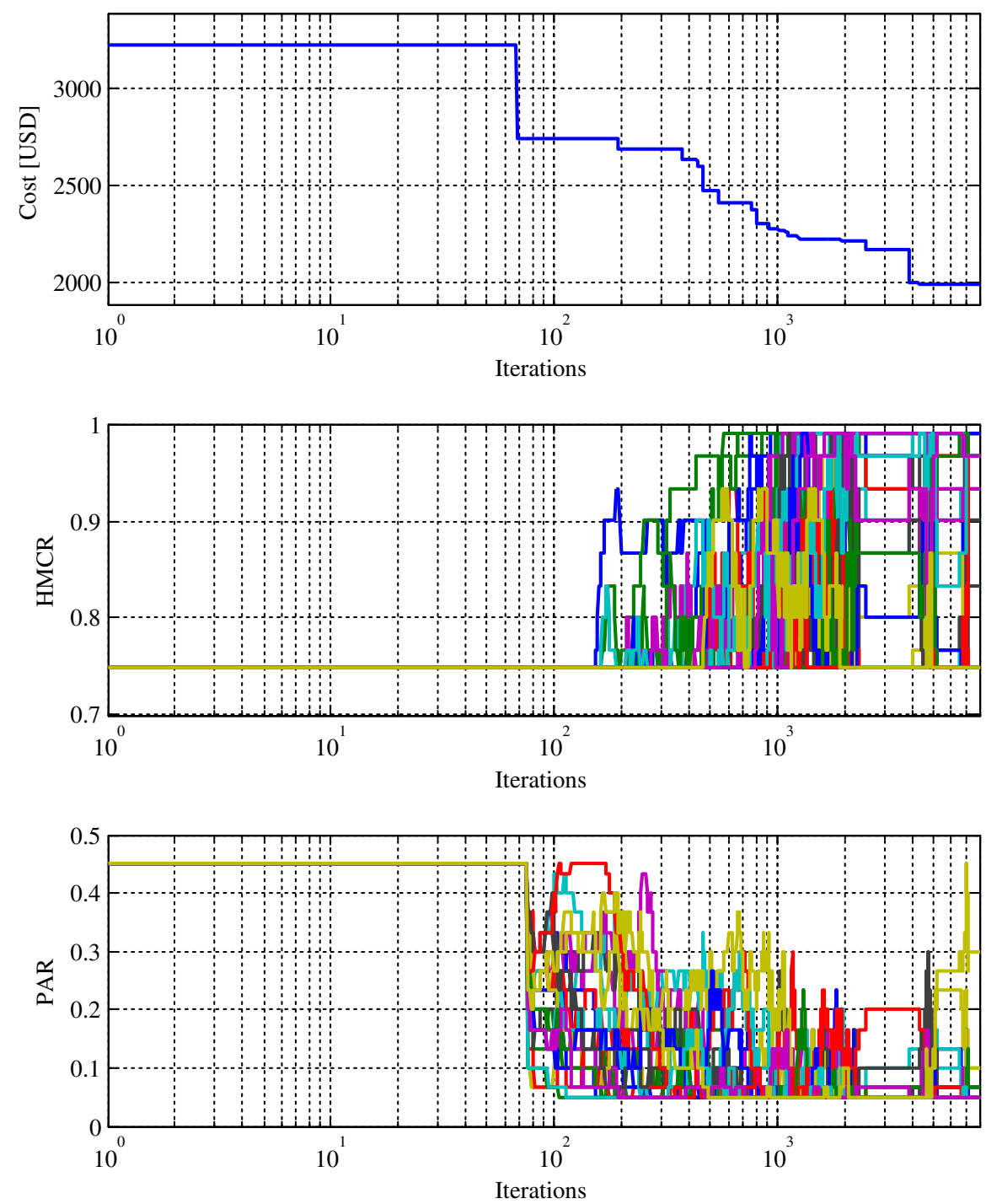

Fig. 14. Design case (5) - best run convergence curves

TABLE XVI

DESIGN CASE (5) - BEST RUN STIRRUPS DISTRIBUTION

\begin{tabular}{ll}
\hline Span No. & $\begin{array}{l}\text { Span reinforcement regions [m] } \\
{[\text { Left, Middle, Right] of span }}\end{array}$ \\
\hline 1 & {$[1.35,1.00,2.50]$} \\
2 & {$[2.05,0.90,2.40]$} \\
3 & {$[1.75,2.00,-]$} \\
\hline$*$ & Numbering starts from the left span to the right span. \\
$* *$ & The regions where the stirrups spacings are distributed.
\end{tabular}

iterations.

$$
\begin{aligned}
\text { MaxItr }=4.07 & \times 10^{4}+2.022 \times 10^{-20} \boldsymbol{\Omega}-3789 \boldsymbol{\Psi} \\
& -6.127 \times 10^{-22} \boldsymbol{\Omega} \boldsymbol{\Psi}+106.2 \boldsymbol{\Psi}^{2}
\end{aligned}
$$

\section{Conclusions}

In the present work, an augmented optimization model to design RC beams according to EC2 norms has been proposed. A modified version of the parameter-setting-free harmony search (PSFHS) algorithm has been used to solve the optimization model. The obtained solutions have been found integratedly and no solution-staging has been used. Hence, the final solutions (design vectors) are not intentionally localized.

Different design cases and boundary conditions have been dealt with in this paper including regular and high-strength reinforced concrete beams. However, it has been found fruitless to compare this paper with other former pieces of literature due to the differences in the proposed optimization models and the used standards, i.e Eurocodes. The modified PSFHS proved its stability and robustness under high-dimensional problems and avoiding local minima comparing to the state-ofart algorithms. Furthermore, Figs. 5, 14, and B.1 show clearly the stable and careful convergence of the method by avoiding locals. However, the robustness of this algorithm requires 


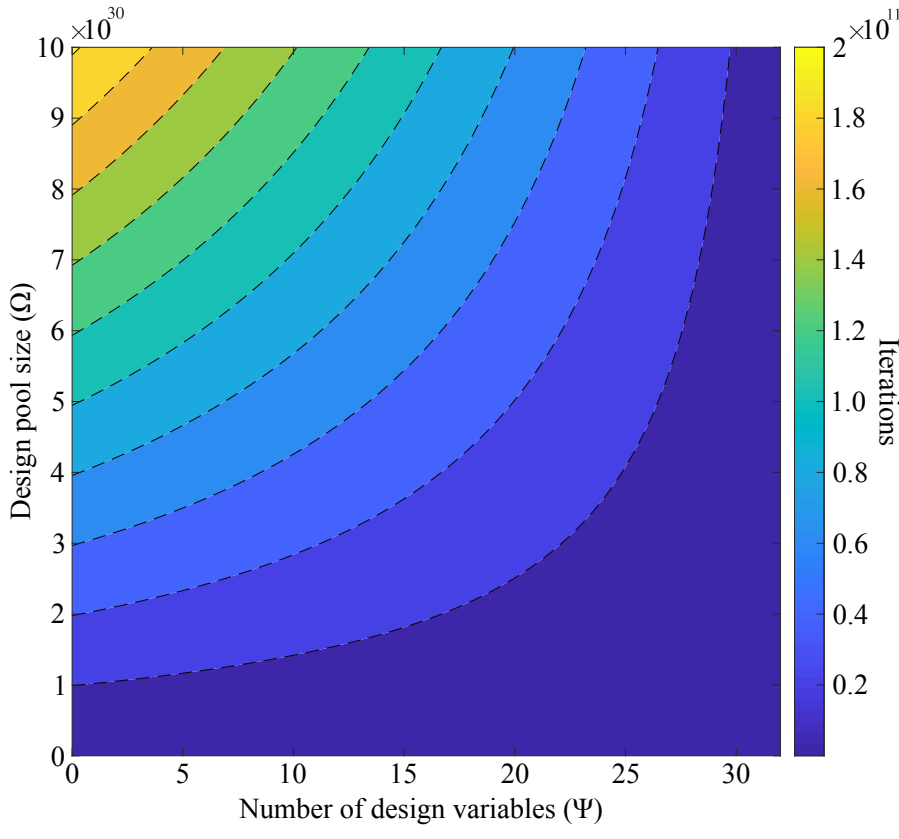

Fig. 15. Number of iterations response function

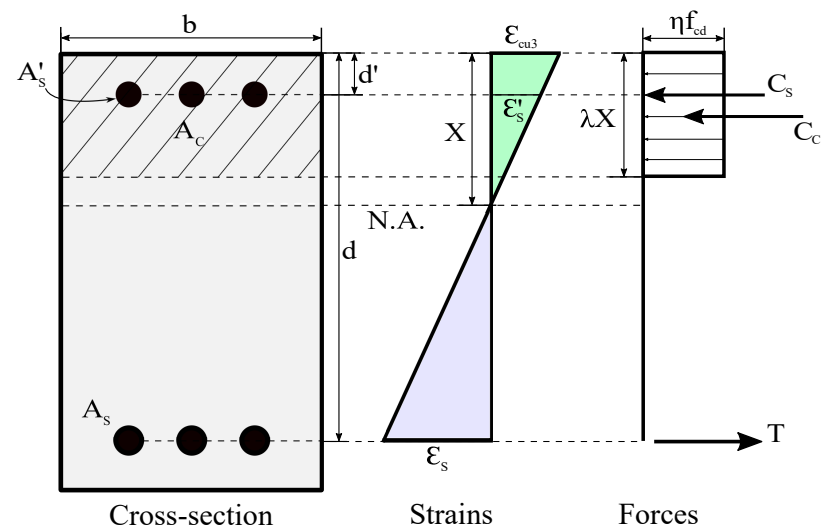

Fig. A.1. Doubly reinforced rectangular beam section

further refinements and investigations into two different levels, the model's level of complexity and the algorithm's level, to provide a more-mature mean to be included in the current BIM software packages.

For the current problem hardness, iteration estimators have been derived to visualize the real complexity, hardness approximation, of the proposed optimization model to find near-optimal solutions. In addition, those derivations can be considered as a one more step toward fully-free-of-setting algorithms.

This algorithm is recommended for solving other RC structural elements, such as columns, walls, etc., associated with a high number of design variables, especially that the proposed model and algorithm need no prior knowledge from the enduser in metaheuristic algorithms. Eventually, applying a largescale parametric study on the modified PSFHS will surely open the doors to new perspectives and applications for it.

\section{APPENDIX A: FLEXURAL REINFORCEMENT}

In this section, a sound direct, computationally less expensive, and a non-iterative bending capacity algorithm has been derived. The following approach, for doubly reinforced sections, replaces the conventional and iterative strain compatibility method [5], [6] in this paper. The first attempt of this algorithm is to evaluate the neutral axis position, refer to Fig. A.1 assuming that both the strains in compression and tension reinforcement yielded simultaneously, while the concrete reached its crushing strain (see (A.1) to A.4).

$$
\begin{gathered}
T=A_{s} f_{y d} \\
C_{c}=\eta f_{c d} \lambda X b \\
C_{s}=A_{s}^{\prime} f_{y d} \\
X=\frac{f_{y d}\left(A_{s}-A_{s}^{\prime}\right)}{\lambda \eta f_{c d} b}
\end{gathered}
$$

After that, the tension and compression steel strains are evaluated from (A.5) and A.6 respectively, that were derived in the first place form the triangulation of the strain distribution assumed in Fig. A.1

$$
\begin{aligned}
& \epsilon_{s}=\epsilon_{c u 3}\left(\frac{d}{X}-1\right) \leq \frac{f_{y d}}{E_{s}} \\
& \epsilon_{s}^{\prime}=\epsilon_{c u 3}\left(1-\frac{d^{\prime}}{X}\right) \leq \frac{f_{y d}}{E_{s}}
\end{aligned}
$$

If the resulted strain in one of them or both, A.5 and A.6, is less than the yield strain it means that the acting forces on the cross-section are not in equilibrium; the first assumption is violated. Attempt two is required, where the general solution is described by A.7, and varies as described in the following cases:

$$
X=\frac{\sqrt{A+B+C+D}+E+F}{2 \lambda \eta b f_{c d}}
$$

- Only the strain of the compression reinforcement yielded. In this case, the tension force, $T$, in steel must be modified in A.1 to be $T=A_{s} E_{s} \epsilon_{s}$, and by solving for the neutral axis depth, the coefficients $A \rightarrow F$ of the general real positive root are depicted in $(\mathrm{A} .8)$ to A.13;

$$
\begin{gathered}
A=A_{s}^{\prime 2} f_{y d}^{2} \\
B=2000 A_{s}^{\prime} A_{s} E_{s} f_{y d} \epsilon_{c u 3} \\
C=10^{6} A_{s}^{2} E_{s}^{2} \epsilon_{c u 3}^{2} \\
D=4000 \lambda \eta b d f_{c d} A_{s} E_{s} \epsilon_{c u 3} \\
E=-10^{3} A_{s} E_{s} \epsilon_{c u 3} \\
F=-A_{s}^{\prime} f_{y d}
\end{gathered}
$$


TABLE B.1

PARAMETER SETTINGS FOR THE MODIFIED AND STANDARD PSFHS

\begin{tabular}{ll}
\hline Parameter & Assigned value \\
\hline MaxItr & 300,000 \\
HMCRi & 0.45 \\
HMCR $_{\text {max }}$ & 0.99 \\
PARi $^{\text {PAR }}$ min & 0.5 \\
HMS $_{m}$ & 0.05 \\
m & 25 \\
$\xi$ & 1.0 \\
\hline
\end{tabular}

- Only the strain in tension reinforcement yielded. In this case, the compression force in steel, $C_{s}$, must be modified in A.3 to be $C_{s}=A_{s}^{\prime} E_{s} \epsilon_{s}^{\prime}$ and A.14) to A.19) describe the coefficients to find the real positive root of A.7);

$$
\begin{gathered}
A=A_{s}^{\prime 2} E_{s}^{2} \epsilon_{c u 3}^{2} \\
B=-2000 A_{s}^{\prime} A_{s} E_{s} f_{y d} \epsilon_{c u 3} \\
C=A_{s}^{2} f_{y d}^{2} \\
D=4000 \lambda \eta b d^{\prime} f_{c d} A_{s}^{\prime} E_{s} \epsilon_{c u 3} \\
E=A_{s} f_{y d} \\
F=-10^{3} A_{s}^{\prime} E_{s} \epsilon_{c u 3}
\end{gathered}
$$

- Both steel strains do not yield. This case is considered impractical and out of the scope of this paper, besides, a well-controlled design algorithm can skip such a case easily.

Note that A.7 to A.19 have been derived where the input units for stresses are in $M P a$, hence $f_{c d}$ and $f_{y d}$, and the moduli of elasticity are expressed in GPa. In addition, the provided areas for both tension and compression reinforcements are in $\mathrm{mm}^{2}$ and all the geometrical dimensions such as $b, d$ and $d^{\prime}$ are in $m m$. Eventually the resulting depth of the neutral axis was declared in $\mathrm{mm}$.

\section{APPENDIX B: SMALL-SCALE BENCHMARKING}

In this section, a small-scale benchmarking was used to compare the modified PSFHS with the Original Harmony Search (OHS) algorithm [7], the standard PSFHS [21] and Cuckoo Search (CS) Algorithm [38]. For this purposes, standard Schwefel function (see [39], [40]) has been chosen with 100 design variables (dimensions).

First, both the standard PSFHS and the proposed modified PSFHS have been compared (refer to Table B.1) to see the parameters setting. Figure B.1 reveals a comparison between the modified PSFHS and standard PSFHS algorithms in solving the Schwefel function.

Elaborately, the modified PSFHS result for 10 independent runs was $-40,180.400 \pm 229.672$, and the best achieved answer was $-40,510.588$. Note that the exact answer of the
TABLE B.2

ORIGINAL HARMONY SEARCH (OHS) ADJUSTMENTS

\begin{tabular}{lllll}
\hline HMS & HMCR & PAR & Iteration & Best fitness \\
\hline \multirow{4}{*}{40} & 0.970 & 0.25 & & $-25,900.61$ \\
& 0.980 & 0.20 & \multirow{2}{*}{300,000} & $-29,666.42$ \\
& 0.990 & 0.15 & & $-34,008.81$ \\
& 0.995 & 0.10 & & $-37,891.24$ \\
\hline
\end{tabular}

TABLE B. 3

CUCKOo SEARCH ALGORITHM (CS) ADJUSTMENTS

\begin{tabular}{lllll}
\hline $\begin{array}{l}\text { Nests } \\
\text { number }\end{array}$ & $\begin{array}{l}\text { Rate of } \\
\text { discovery }\end{array}$ & $\begin{array}{l}\text { Number of } \\
\text { generations }\end{array}$ & $\begin{array}{l}\text { Number of } \\
\text { evaluations }\end{array}$ & Fitness \\
\hline 100 & & 1,508 & 300,092 & $-22,874.83$ \\
70 & & 2,159 & 300,102 & $-22,444.24$ \\
50 & 0.10 & 3,031 & 300,070 & $-22,718.47$ \\
30 & & 5,084 & 300,016 & $-21,827.67$ \\
10 & & 15,790 & 300,011 & $-23,041.04$ \\
10 & 0.01 & 15,790 & 300,011 & $-24,326.99$ \\
5 & 0.10 & 33,334 & 300,006 & $-23,101.69$ \\
\hline
\end{tabular}

function, using 100 dimensions, is $-41,898.290$. Regarding the standard PSFHS, the overall result was $-17,202.608 \pm$ $1,870.637$, and the best run scored was 20,091.100.

The OHS has been tested and adjusted accordingly to solve this problem. Table B.2 explains different solutions obtained with different adjustments and evaluations, where it functioned potentially better than the standard PSFHS for the same problem size.

Finally, the CS algorithm has been used to solve the same problem in this section. Fine-tuning has been implemented to obtain the best answer using different generation numbers in order to keep the number of computational efforts nearly equal and to get a sounds-fair comparison. Table B.3 shows the different results obtained with different settings.

\section{ApPEndix C: Miscellaneous Results}

In this section, the results of the fourth design case have been shown in detail. Figure C.1 illustrates the ultimate and serviceability envelopes as per the Eurocodes [22], [23], [41], [42], [43], while Table C.1 explains the results of the maximum deflection for each span taking into account the shrinkage and creep effects for long term time-spans.

\section{REPLICATION OF RESULTS}

The datasets generated during the current study are not publicly available due to the dependency of such algorithms on the time seeds used by the pseudo-random number generator

TABLE C.1

DESIGN CASE (4) - THE FINAL DEFLECTION RESULTS OBTAINED

\begin{tabular}{ll}
\hline Span No. & Mid-span deflection [mm] \\
\hline 1 & 6.811 \\
2 & $-3.569^{* *}$ \\
3 & 0.640 \\
\hline$*$ Numbering starts from the left span to the right span. \\
$* *$ Flipped sign due to the shrinkage effects \\
\hline
\end{tabular}




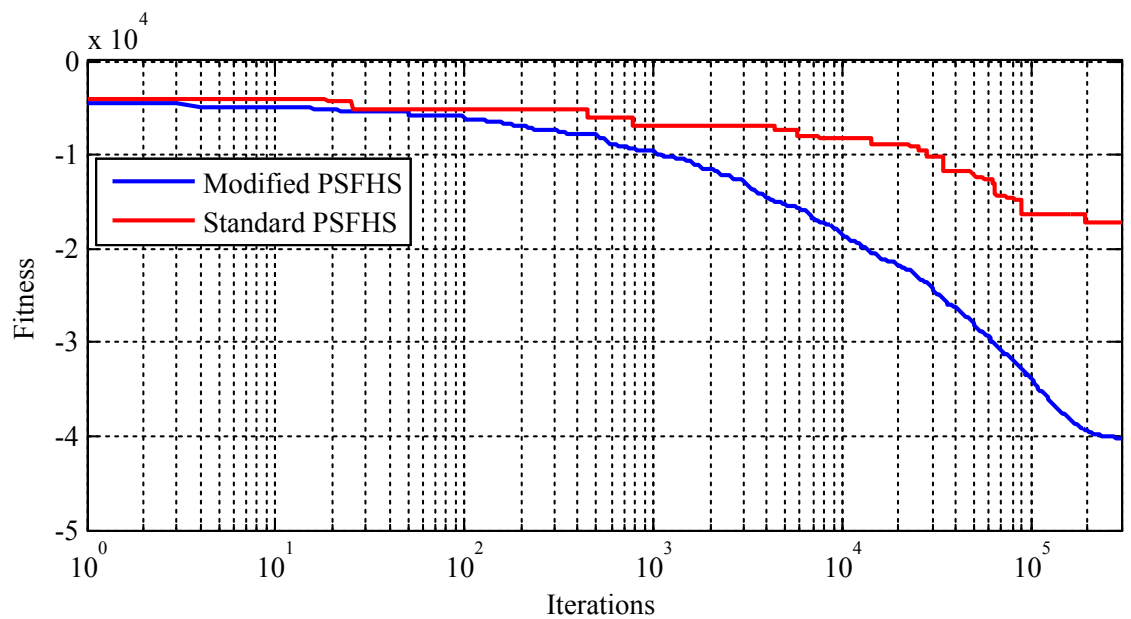

Fig. B.1. Convergence of the modified vs. the standard PSFHS
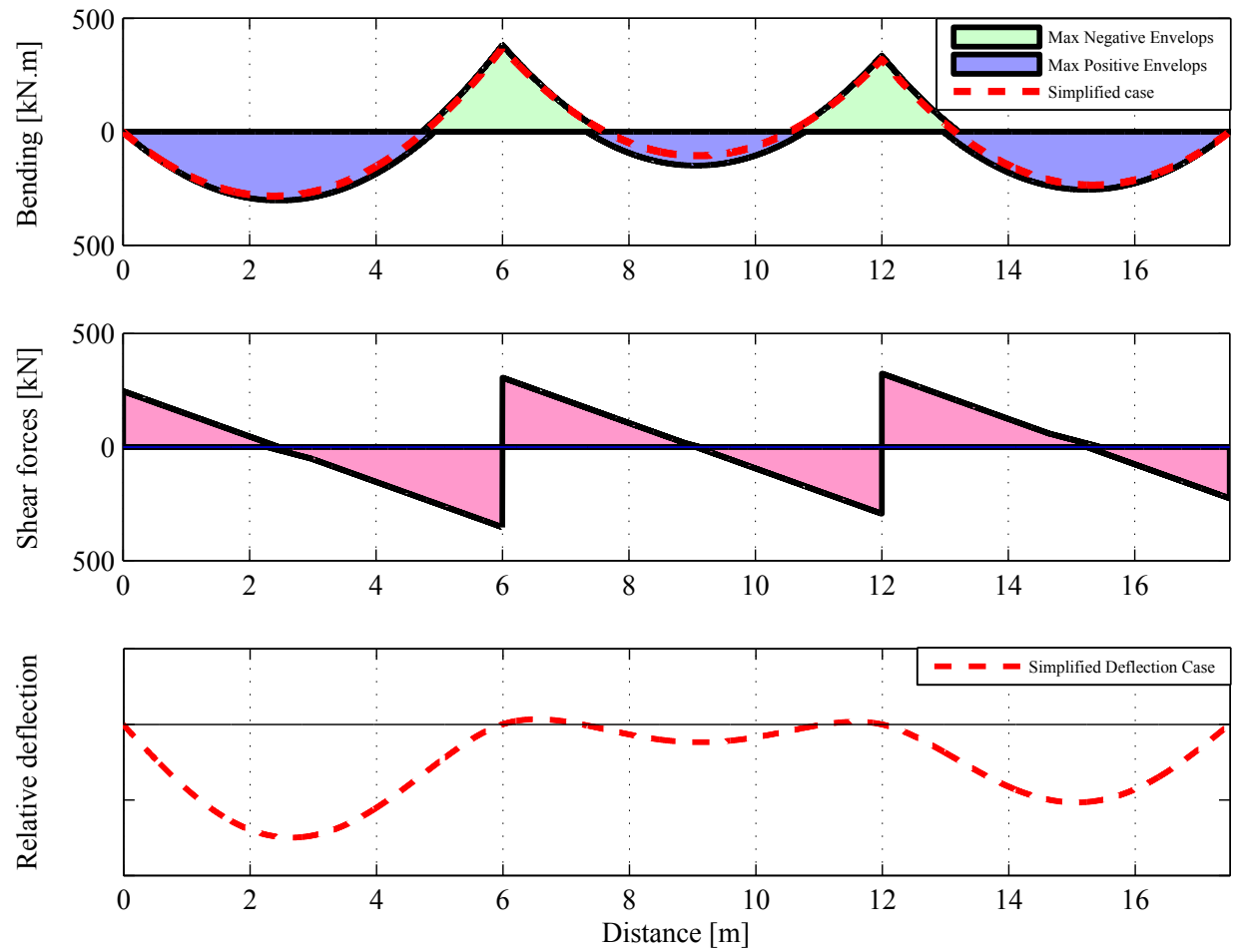

Fig. C.1. Design case (4) - Ultimate Limit State (ULS) and Serviceability Limit States (SLS) envelops

to generate the results. However, we published $\mathrm{C}++14$, Python 3.7 and Matlab codes that allow the reader to reproduce and replicate the results of the Schwefel function, refer to Appendix B. The complete manuscripts, source codes, that were generated during the current study are not publicly available; they could be subjected to commercial copyrights soon, yet they are available from the corresponding author as per reasonable request. The abovementioned codes shall be found on the online repository: https://doi.org/10.5281/zenodo.2573261 (see [44]).

\section{CONFLICT OF INTEREST}

The authors declare that they have no conflict of interest. However, this document is an author-customized preprint version. The original article shall be found on the following link: https://doi.org/10.1007/s00158-019-02252-4. This work shall be cited and referred to as shown on the publisher website: Shaqfa, M. \& Orbán, Z. Struct Multidisc Optim (2019). 


\section{REFERENCES}

[1] H. Rahami, A. Kaveh, and Y. Gholipour, "Sizing, geometry and topology optimization of trusses via force method and genetic algorithm," Engineering Structures, vol. 30, no. 9, pp. 2360 - 2369, 2008. [Online]. Available: http://www.sciencedirect.com/science/article/ pii/S0141029608000163

[2] A. Akin and M. Saka, "Optimum detailed design of reinforced concrete continuous beams using the harmony search algorithm," Proceedings of the Tenth International Conference on Computational Structures Technology, vol. 93, 012010.

[3] J. Calavera, Manual for Detailing Reinforced Concrete Structures to EC2. CRC Press, 2014.

[4] Institution of Structural Engineers (Great Britain) and Concrete Society, Standard method of detailing structural concrete =: A manual for best practice. Institution of Structural Engineers, 2006.

[5] A. W. Beeby, R. S. Narayanan, and H. Gulvanessian, Designers' Guide to Eurocode 2: Design of Concrete Structures, H. Gulvanessian, Ed. Thomas Telford Publishing, 2005. [Online]. Available: https: //www.icevirtuallibrary.com/doi/abs/10.1680/dgte2docs.31050

[6] P. Bhatt, T. Macginley, and B. Choo, Reinforced Concrete: Design Theory and Examples. Taylor \& Francis, 2006. [Online]. Available: http://eprints.gla.ac.uk/33312/

[7] Z. W. Geem, J. H. Kim, and G. Loganathan, "A new heuristic optimization algorithm: Harmony search," SIMULATION, vol. 76, no. 2, pp. 60-68, 2001. [Online]. Available: https://doi.org/10.1177/ 003754970107600201

[8] M. M. Jahjouh, M. H. Arafa, and M. A. Alqedra, "Artificial bee colony (abc) algorithm in the design optimization of rc continuous beams," Structural and Multidisciplinary Optimization, vol. 47, no. 6, pp. 963-979, Jun 2013. [Online]. Available: https://doi.org/10.1007/s00158-013-0884-y

[9] M. Mangal and J. C. Cheng, "Automated optimization of steel reinforcement in rc building frames using building information modeling and hybrid genetic algorithm," Automation in Construction, vol. 90, pp. 39 - 57, 2018. [Online]. Available: http://www.sciencedirect. com/science/article/pii/S0926580517305630

[10] V. Govindaraj and J. Ramasamy, "Optimum detailed design of reinforced concrete continuous beams using genetic algorithms," Computers \& Structures, vol. 84, no. 1, pp. 34 - 48, 2005. [Online]. Available: http://www.sciencedirect.com/science/article/pii/S004579490500310X

[11] J. H. Holland, Adaptation in Natural and Artificial Systems. Cambridge, MA, USA: MIT Press, 1992

[12] S. Chutani and J. Singh, "Evaluation of enhanced particle swarm optimization techniques for design of rc structural elements," Journal of Materials and Engineering Structures JMES , vol. 4, no. 2, pp. 65-78, 2017. [Online]. Available: http://revue.ummto.dz/index.php/ JMES/article/view/1498

[13] M. Alqedra, M. Arafa, and I. Mohammed, "Optimum cost of prestressed and reinforced concrete beams using genetic algorithms," Journal of Artificial Intelligence, vol. 4, 012011.

[14] K. T. Kong J., "Preliminary design of concrete structures using genetic algorithms and spreadsheets," 31st Conference on OUR WORLD IN CONCRETE \& STRUCTURES, 2006.

[15] S. A Babiker, F. Adam, and A. E Mohamed, "Design optimization of reinforced concrete beams using artificial neural network," International Journal of Engineering Inventions ISSN, pp. 2278-7461, 012012

[16] Y. X. Bekdas G., Nigdeli S., "Metaheuristic optimization for the design of reinforced concrete beams under flexure moments," Proceedings of the 5th European Conference of Civil Engineering (ECCIE'14), 2014.

[17] S. M. N. Gebrail Bekdas, "Optimum design of reinforced concrete beams using teaching-learning-based optimization," 2015.

[18] Z. B. Matej Leps, "Applying genetic algorithms to optimization of reinforced concrete beam," CTU, Fac. of Civil Eng., Dep. of Structural Mechanics Thakurova 7, 16629 Prague 6, 1999.

[19] P. S. A. Bhalchandra, "Cost optimization of doubly reinforced rectangular beam section," International Journal of Modern Engineering Research (IJMER), 2012

[20] A. R. Kulkarni and V. Bhusare, "Structural optimization of reinforced concrete structures," International Journal of Engineering Research and, vol. V5, 072016.

[21] Z. W. Geem and K.-B. Sim, "Parameter-setting-free harmony search algorithm," Applied Mathematics and Computation, vol 217, no. 8, pp. 3881 - 3889, 2010. [Online]. Available: http: //www.sciencedirect.com/science/article/pii/S009630031001009X

[22] EN 1992-1-1 Eurocode 2: Design of concrete structures - Part 1-1: General ruels and rules for buildings, EN. Brussels: CEN, 2005.
[23] H. Gulvanessian, "En1991 eurocode 1: Actions on structures," Proceedings of the Institution of Civil Engineers - Civil Engineering, vol. 144, no. 6, pp. 14-22, 2001. [Online]. Available: https: //doi.org/10.1680/cien.2001.144.6.14

[24] H. A. J. H. T. M. R. M. N. R. S. W. R. Bond A. J., Brooker O., How to Design Concrete. Structures using Eurocode 2, 2006.

[25] M. Birrattari, L. Paquete, T. Stützle, and K. Varrentrapp, Classification of metaheuristics and design of experiments for the analysis of components. Darmstadt: Techn. Univ., FB 20, FG Intellektik, January 2001, vol. AIDA-0. [Online]. Available: http://tubiblio.ulb.tu-darmstadt.de/17608/

[26] J. H. Kim, H. M. Lee, and D. G. Yoo, "Investigating the convergence characteristics of harmony search," in Harmony Search Algorithm, J. H. Kim and Z. W. Geem, Eds. Berlin, Heidelberg: Springer Berlin Heidelberg, 2016, pp. 3-10.

[27] I. Kougias and N. Theodossiou, "A new music-inspired harmony based optimization algorithm. theory and applications,", 012010

[28] Z. W. Geem, J. Kim, and G. V Loganathan, "Harmony search optimization: Application to pipe network design," International Journal of Modelling and Simulation, vol. 22, 012002.

[29] O. Hasanebi, F. Erdal, and M. P. Saka, "Adaptive harmony search method for structural optimization," Journal of Structural Engineering, vol. 136, no. 4, pp. 419-431, 2010. [Online]. Available: https:// ascelibrary.org/doi/abs/10.1061/\%28ASCE\%29ST.1943-541X.0000128

[30] Z. W. Geem, "Novel derivative of harmony search algorithm for discrete design variables," Applied Mathematics and Computation, vol. 199, no. 1, pp. 223 - 230, 2008. [Online]. Available: http://www.sciencedirect.com/science/article/pii/S0096300307009897

[31] K. S. Lee and Z. W. Geem, "A new meta-heuristic algorithm for continuous engineering optimization: harmony search theory and practice," Computer Methods in Applied Mechanics and Engineering, vol. 194, no. 36, pp. 3902 - 3933, 2005. [Online]. Available: http://www.sciencedirect.com/science/article/pii/S0045782504004682

[32] A. Olsson, G. Sandberg, and O. Dahlblom, "On latin hypercube sampling for structural reliability analysis," Structural Safety, vol. 25 , no. 1 , pp. 47 - 68, 2003. [Online]. Available: http://www.sciencedirect. com/science/article/pii/S0167473002000395

[33] Z. W. Geem, "Optimal cost design of water distribution networks using harmony search," Engineering Optimization, vol. 38, no. 3, pp. 259-277, 2006. [Online]. Available: https://doi.org/10.1080/03052150500467430

[34] L. Bianchi, M. Dorigo, L. M. Gambardella, and W. J. Gutjahr, "A survey on metaheuristics for stochastic combinatorial optimization,' Natural Computing, vol. 8, no. 2, pp. 239-287, Jun 2009. [Online]. Available: https://doi.org/10.1007/s11047-008-9098-4

[35] K. Srensen, "Metaheuristicsthe metaphor exposed," International Transactions in Operational Research, vol. 22, no. 1, pp. 3-18, 2015. [Online]. Available: https://onlinelibrary.wiley.com/doi/abs/10.1111/itor. 12001

[36] X.-S. Yang, S. Deb, and S. Fong, "Metaheuristic algorithms: Optimal balance of intensification and diversification," Applied Mathematics \& Information Sciences, vol. 8, 082013

[37] R. T. Marler and J. S. Arora, "The weighted sum method for multiobjective optimization: new insights," Structural and Multidisciplinary Optimization, vol. 41, no. 6, pp. 853-862, Jun 2010. [Online]. Available: https://doi.org/10.1007/s00158-009-0460-7

[38] X. Yang and Suash Deb, "Cuckoo search via lvy flights," in 2009 World Congress on Nature Biologically Inspired Computing (NaBIC), Dec 2009, pp. 210-214

[39] S. Surjanovic and D. Bingham, "Virtual library of simulation experiments: Test functions and datasets," Retrieved October 3, 2018, from http://www.sfu.ca/ $\sim$ ssurjano

[40] - "Virtual library of simulation experiments: Test functions and datasets," Retrieved October 3, 2018, from http://www.sfu.ca/ $\sim_{\text {ssurjano }}$

[41] Federation internationale du beton. Task Group 4.4, Practitioners' Guide to Finite Element Modelling of Reinforced Concrete Structures: Stateof-the-art Report, ser. Bulletin (fib Fédération internationale du béton). International Federation for Structural Concrete (fib), 2008

[42] R. C. Hibbeler, Structural Analysis, 10th ed. Prentice Hall, 2018

[43] D. L. Logan, A First Course in the Finite Element Method, 5th ed. Cengage Learning, 2012.

[44] M. Shaqfa and Z. Orbán, "Codes: Modified parameter-setting-free harmony search (PSFHS) algorithm for optimizing the design of reinforced concrete beams," Nov. 2018. [Online]. Available: https://doi.org/10.5281/zenodo.2573261 